\title{
Uranium Enrichment \\ Export Control Guide: \\ Gaseous Diffusion
}

Nev 06089

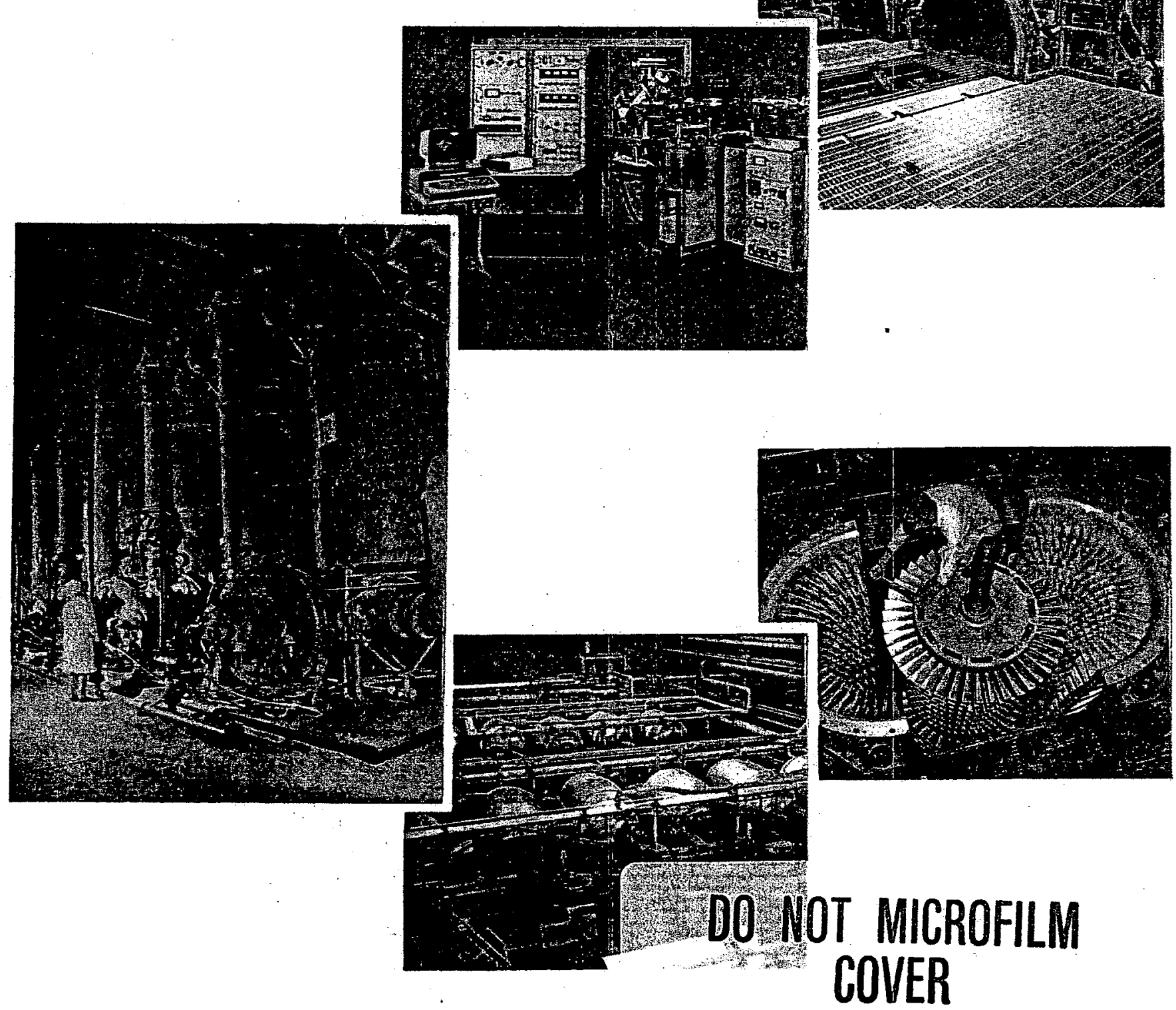

September 1989

MARTIN MARIETRA

MARTIN MARIETTA ENERGY SYSTEMS, INC

Prepared by the International Technology Programs Division for the U.S. Department of Energy, Office of Classification and Technology Policy, and for the U.S. Department of State, Office of Nuclear Export Control, Washington, D.C. 


\section{DISCLAIMER}

This report was prepared as an account of work sponsored by an agency of the United States Government. Neither the United States Government nor any agency Thereof, nor any of their employees, makes any warranty, express or implied, or assumes any legal liability or responsibility for the accuracy, completeness, or usefulness of any information, apparatus, product, or process disclosed, or represents that its use would not infringe privately owned rights. Reference herein to any specific commercial product, process, or service by trade name, trademark, manufacturer, or otherwise does not necessarily constitute or imply its endorsement, recommendation, or favoring by the United States Government or any agency thereof. The views and opinions of authors expressed herein do not necessarily state or reflect those of the United States Government or any agency thereof. 


\section{DISCLAIMER}

Portions of this document may be illegible in electronic image products. Images are produced from the best available original document. 


\section{Uranium Enrichment Export Control Guide: Gaseous Diffusion}

Prepared by the International Technology Programs Division for the US. Department of Energy, Office of Classification and Technology Policy, and for the US. Department of State, Office of Nuclear Export Control, Washington, D.C.

September 1989

MARTIN MARIETTA ENERGY SYSTEMS, INC. Oak Ridge, Tennessee 37831 under Contract No. DE-AC0584OR21400 with the U.S. DEPARTMENT OF ENERGY 
Foreword $\mathrm{v}$

Acknowledgments vii

Introduction 1

Gaseous Diffusion

Uranium Enrichment 3

Steps Used To Prepare

Trigger List Controls 7

Special Materials of Construction ................................9

Descriptions of Controlled Items ........................... 11

1. Assemblies and Components ............................... 13

1.1 Gaseous Diffusion Barriers ................... 17

1.2 Diffuser Housings .................................21

1.3 Compressors and Gas Blowers ............25

1.4 Rotary Shaft Seals ...............................29

1.5 Heat Exchangers for Cooling UF ${ }_{6} \ldots \ldots . . .33$

2. Auxiliary Systems, Equipment, and Components .37

2.1 (a) Feed Systems ......................................39

2.1 (b) Product and Tails Withdrawal Systems

2.2 Header Piping Systems

2.3 Vacuum Systems

2.4 Special Shutoff and Control Valves .....53

$2.5 \quad$ UF $_{6}$ Mass Spectrometers/Ion Sources .59

Appendix: Gaseous Diffusion Trigger List 61 


\section{Foreword}

This document was prepared to serve as a guide for export control officials in their interpretation, understanding, and implementation of export laws that relate to the Zangger International Trigger List for gaseous diffusion uranium enrichment process components, equipment, and materials. Particular emphasis is focused on items that are especially designed or prepared since export controls are required for these by States that are party to the International Nuclear Nonproliferation Treaty. 


\section{Acknowledgments}

Photographs and diagrams of Soviet, French, and U.S. gaseous diffusion technologies were provided by the State Committee on the Utilization of Atomic Energy (U.S.S.R.), Eurodif (France), and the U.S. Department of Energy, Office of Uranium Enrichment, respectively. 


\section{Introduction}

\section{NUCLEAR EXPORT CONTROLS: THE NONPROLIFERATION TREATY}

The International Nuclear Nonproliferation Treaty states in Article III, paragraph 2 (b) that "each State party to the treaty undertakes not to provide equipment or material especially designed or prepared for the processing, use or production of special fissionable material, to any non-nuclear weapon State for peaceful purposes, unless the source or special fissionable material shall be subject to the safeguards required by this article."

\section{CLARIFICATIONS TO THE TREATY: THE TRIGGER LIST}

In its original form, the treaty did not specifically elaborate on, or define the meaning of, "especially designed or prepared" with reference to equipment or material. Furthermore, the terms "processing, use or production" for special fissionable material were not delineated. As a result, necessary definitions and clarifications of the intent of the treaty were prepared to facilitate its implementation. These clarifications consisted of a list of especially designed or prepared equipment or material referred to as the "Trigger List," which is described in International Atomic Energy Agency information circular INFCIRC/209 dated September 3, 1974, and subsequent addenda. Items that appear on the Trigger List require, or trigger the requirement of, safeguards on their export to nonnuclear weapons States.

\section{CONTROLS ON URANIUM ENRICHMENT}

Uranium enrichment was first mentioned in INFCIRC/209 as follows:

"2.5.1 Equipment, other than analytical instruments, especially designed or prepared for the separation of the isotopes of uranium."

In 1979 the above definition was clarified in INFCIRC/209/Mod. 1 as including the following:

"Such items include: gaseous diffusion barriers gaseous diffuser housings 
gas centrifuge assemblies, corrosion resistant to $\mathrm{UF}_{6}$

jet nozzle separation units

vortex separation units

large $\mathrm{UF}_{6}$ corrosion-resistant axial or

centrifugal compressors

special compressor seals for such compressors."

In 1984 an extensive review of gas centrifuge uranium enrichment processing led to a Trigger List clarification that appears in the Annex to INFCIRC/209. The single entry "gas centrifuge assemblies" was extended to include nine especially designed or prepared components of the gas centrifuge itself and four items relating to auxiliary systems, equipment, and components.

\section{GASEOUS DIFFUSION EXPORT CONTROLS}

In 1987-1989 an extensive review of gaseous diffusion uranium enrichment processing led to a Trigger List clarification that will appear in the Annex to INFCIRC/209. The four entries - gaseous diffusion barriers, gaseous diffuser housings, $\mathrm{UF}_{6}$ compressors, and special compressor seals - were expanded to include assemblies, components, auxiliary systems, and auxiliary components especially designed or prepared for gaseous diffusion uranium enrichment.

This guide was prepared to assist export officials in the interpretation, understanding, and implementation of export laws relating to the Zangger International Trigger List for gaseous diffusion process equipment, components, and materials. The nuclear fuel cycle, uranium enrichment, and the gaseous diffusion process are briefly described; steps used to prepare Trigger List controls are cited; descriptions of controlled items are given; and special materials of construction are noted. This is followed by a comprehensive description of especially designed or prepared equipment, materials, and components of the gaseous diffusion process together with pictorial representations. The Trigger List, the nomenclature of which has been retained in the numbered sections of this document, is divided into two parts:

1. especially designed or prepared assemblies and components for use in gaseous diffusion enrichment, and

2. especially designed or prepared auxiliary systems, equipment, and components for use in gaseous diffusion enrichment. 


\section{Gaseous Diffusion}

\section{Uranium Enrichment}

Most of the nuclear power plants in the world today are designed to use uranium enriched to approximately $3 \%{ }^{235} \mathrm{U}$ as fuel, while weapons can use uranium enriched to approximately $90 \%$. As found in nature, uranium consists principally of two isotopes: ${ }^{235} \mathrm{U}$ and ${ }^{238} \mathrm{U}$.* The ${ }^{235} \mathrm{U}$ isotope is fissionable, and this property of being able to split and to give up heat makes it useful in both nuclear reactors and weapons. The ${ }^{235} U$ isotope is present in the amount of only $0.711 \%$ by weight in natural uranium.

A number of interrelated steps are involved in locating, preparing, and using uranium for reactors and weapons. Enrichment, an important step in producing nuclear materials, can increase the assay of ${ }^{235} \mathrm{U}$ from $0.711 \%$ to almost pure concentrations. Separation of the natural mixture of uranium isotopes is a difficult task because such heavy isotopes behave almost identically in most chemical and physical processes. An intensive survey has been under way for many years to identify and to develop processes that have potential for isotope separation. The early research efforts were concentrated on electromagnetic processes, gaseous diffusion, thermal diffusion, and gas centrifugation. Although production-scale uranium enrichment plants using the first three of these processes were successfully built in the 1940s, the advantages of the gaseous diffusion process were quickly demonstrated. As a result of continued research and development of enrichment techniques in the last forty years, the technology now exists to enrich uranium for reactors and weapons efficiently by the process of gaseous diffusion.

\section{GASEOUS DIFFUSION PROCESS}

Today most of the world capacity for uranium enrichment is provided by gaseous diffusion, a process that has been in continuous use on a large scale in the United States since 1948. In concept, it is a simple process based on the fact that the velocity of a gas molecule at a given

*Isotopes are atoms of the same chemical element - very similar in chemical behavior but distinguishable by differences in atomic weight, radioactioe transformations, etc. 


\section{NUCLEAR FUEL CYCLE}

(1)

MINING

TYPICAL ORE CONTAINS

ABOUT $0.14 \% \mathrm{U}_{3} \mathrm{O}_{8}$
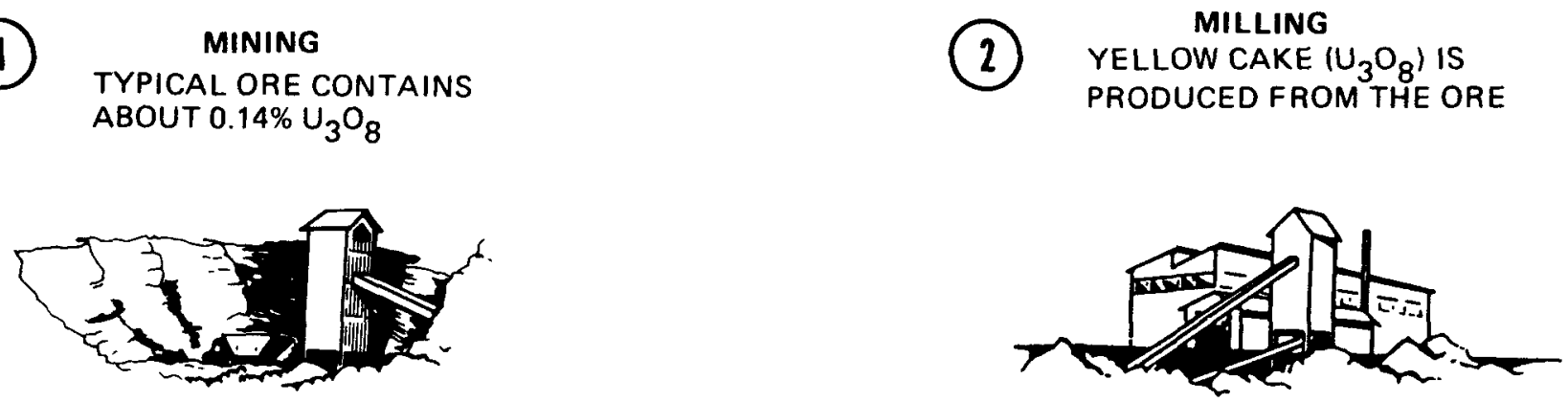

(1)

ENRICHMENT

URANIUM HEXAFLUORIDE

WITH $0.711 \% 235 \mathrm{U}$ IS ENRICHED

TO $3 \% 235 \mathrm{U}$

(6) POWER REACtOR

ABOUT ONE-THIRD OF FUEL

IN REACTOR REPLACED

EACH YEAR

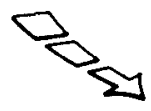

SPENT FUEL

INTERIM STORAGE OF

SPENT FUEL PENDING

POSSIBLE REPROCESSING

OR PERMANENT STORAGE
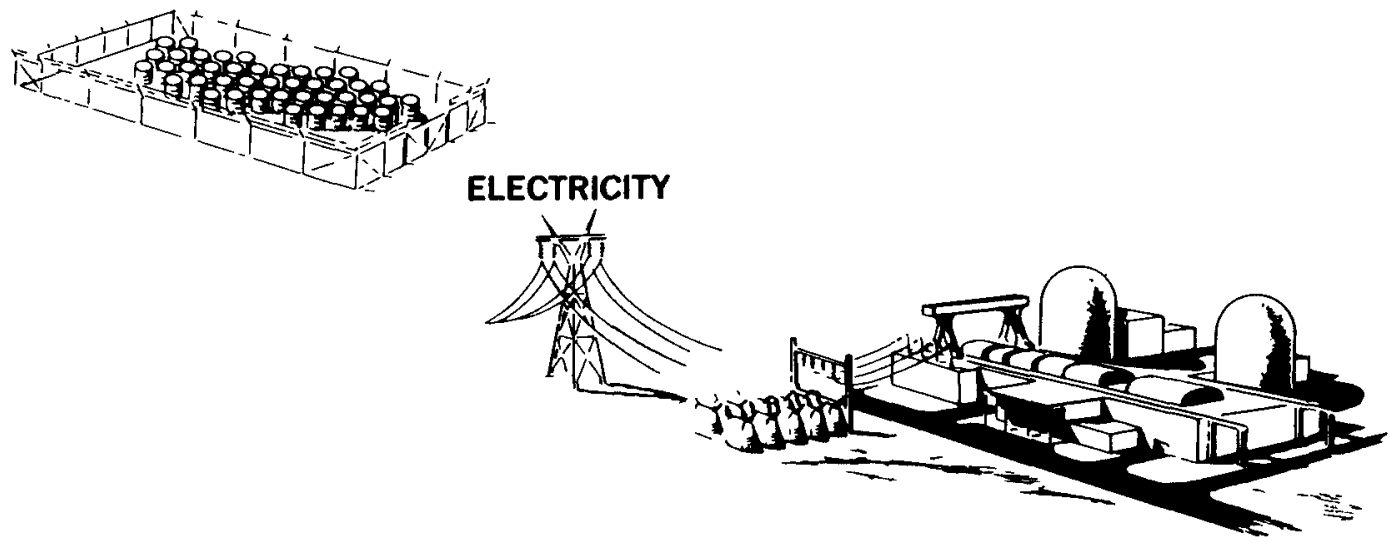
CONVERSION

GASEOUS URANIUM

(3) HEXAFLUORIDE $\left(\mathrm{UF}_{6}\right)$

IS PRODUCED FROM

YELLOW CAKE AND

FLUORINE

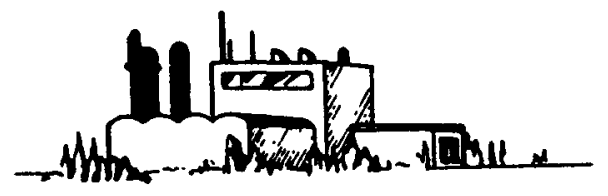

5) FUEL FABRICATION

POWER PLANT FUEL PRODUCED

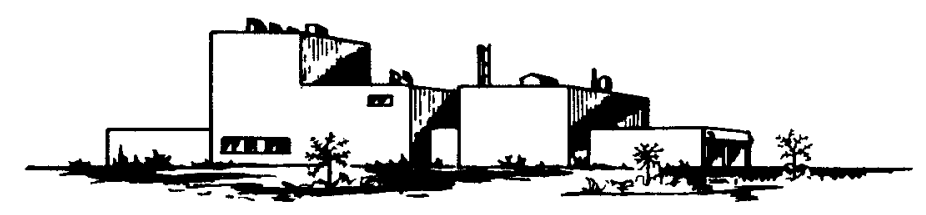

(7) REPROCESSING

SPENT NUCLEAR FUEL IS PROCESSED TO

RECOVER URANIUM

AND PLUTONIUM FOR

RECYCLE temperature depends on the mass of the molecule. In the gaseous diffusion process, uranium hexafluoride $\left(\mathrm{UF}_{6}\right)$ molecules bearing ${ }^{235} \mathrm{U}$ have a higher random molecular velocity; the gas that passes through the barrier pores is slightly enriched in the ${ }^{235} \mathrm{U}$ isotope, and the gas that does not pass through is depleted in the ${ }^{235} \mathrm{U}$. The enrichment obtained in a single diffusion operation is quite small. To enrich ${ }^{235} U$ to concentrations above $90 \%$, this diffusion process must be repeated thousands of times by coupling the diffuser units in series.

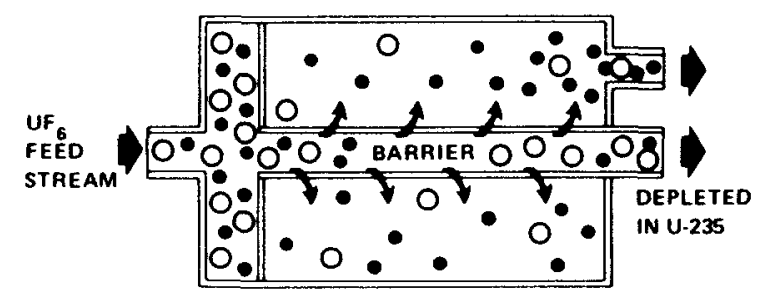

The gaseous diffusion process for uranium enrichment is based upon the fact that lighter molecules flow slightly faster than heavier molecules through the walls of a porous tube called a barrier. The portion of gas passing through the barrier wall is slightly richer in ${ }^{235} U$. The molecular speeds of the two types of $U F_{6}$ molecules differ by only about $0.4 \%$.

\section{DIFFUSION PROCESS IMPLEMENTATION}

The next figure depicts typical equipment used in the gaseous diffusion process. The basic building block of this cascade is called a stage, and eight are shown here in a grouping known as a cell. Each stage is composed of a diffuser vessel, a gas compressor, a motor, a control valve, and the associated piping.

The diffuser vessel contains tubular barrier material that actually performs the isotopic enrichment and a gas cooler or heat exchanger to control the stage temperature. The key to the success of the entire process is the barrier material itself. The gas cooler, operating on the low-pressure diffused gas, removes about $95 \%$ of the energy added to the gas by the compressor. The individual diffusers containing the barrier tubes are quite large. 


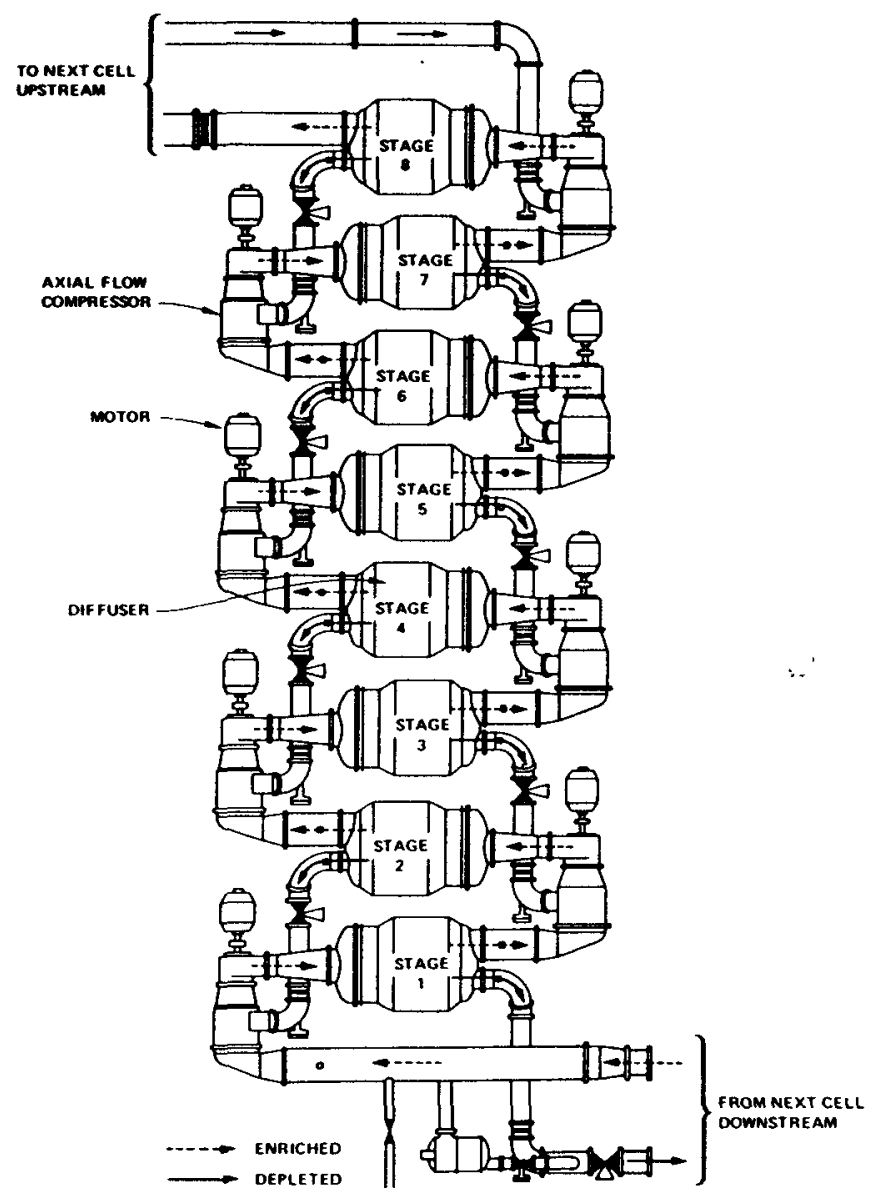

Typical U.S. gaseous diffusion equipment

Normally, axial flow or centrifugal compressors are used to compress the UF 6 gas to the pressures needed to cause the gas flow through the barrier tubes and from one stage to another. The gas compressors are powered by electrical motors.

Control valves are necessary to adjust the gas flow and pressure conditions to obtain the best performance from both the barrier and the compressors. The pressure drop caused by this valve cannot be very large since this represents a source of stage power inefficiency. Large block valves are used between successive groups of eight to ten stages to allow isolating stages for maintenance.

In addition to the process stage equipment, the gaseous diffusion plants require auxilliary systems, such as the uranium hexafluoride feed and withdrawal systems, an extensive electrical power distribution system, and cooling towers to dissipate the waste process heat. 
The following actions were taken to prepare the Trigger List:

- developed a comprehensive, preliminary list of equipment, materials, and technology;

- established priorities for items on the developed list based on their uniqueness of function or design features;

- developed simplified descriptions that contain key specifications;

- determined domestic and foreign suppliers;

- evaluated potential impacts on suppliers that could result from establishment of controls on each individual item;

- evaluated potential effectiveness of proposed controls;

- identified and determined alternatives as required;

- refined the list of items by avoiding end-use specifications whenever possible;

- initiated bilateral discussions; and

- initiated multilateral discussions among technology holders and key supplier States.

The International Zangger Committee then adopted a Trigger List of the gaseous diffusion process equipment, components, and materials. 


\section{Special Materials of Construction}

The gaseous diffusion uranium enrichment process relies on the use of uranium in a volatile gaseous form: uranium hexafluoride $\left(\mathrm{UF}_{6}\right)$. This is pumped from stage to stage through a special diffusion barrier. Because $\mathrm{UF}_{6}$ is a very corrosive gas, similar to fluorine in this respect, all process surfaces that come into direct contact with this gas must be fabricated or lined with special materials. Such materials include stainless steel, aluminum, aluminum alloys, aluminum oxide, nickel or its alloys containing $60 \%$ or more nickel, and $\mathrm{UF}_{6}$-resistant fully fluorinated hydrocarbon polymers. 


\section{Descriptions of Controlled Items}

The descriptions, special design features, photographs, and sketches of gaseous diffusion components, equipment, and materials that follow are intended to be representative of typical gaseous diffusion uranium enrichment plants. Because of the wide variety of specific process designs that are possible, there may be a considerable difference in the appearance of equipment and components for any one given design from that given in the photographs and sketches shown in this guide. Space limitations preclude the inclusion in this guide of all possible variants; however, illustrations representative of Soviet, French, and U.S. gaseous diffusion technologies are shown. For each item on the control list, a description of the item, its special design features, and a photograph or sketch is given. The descriptions are taken verbatim from the Zangger International Trigger List. 
12 
and

\section{Components}

\section{DESCRIPTION}

Especially designed or prepared assemblies and components for use in gaseous diffusion enrichment

\section{SPECIAL}

\section{DESIGN FEATURES}

In the gaseous diffusion method of uranium isotope separation, the main technological assembly is comprised of a special porous gaseous diffusion barrier, a heat exchanger for cooling the gas (which is heated by the process of compression), seal valves and control valves, and pipelines. Inasmuch as gaseous diffusion technology uses $\mathrm{UF}_{6}$, all equipment, pipeline, and instrumentation surfaces (that come in contact with the gas) must be made of materials that remain stable in contact with $\mathrm{UF}_{6}$. A gaseous diffusion facility requires a large number of these assemblies, so quantities can provide an important indication of end use. 

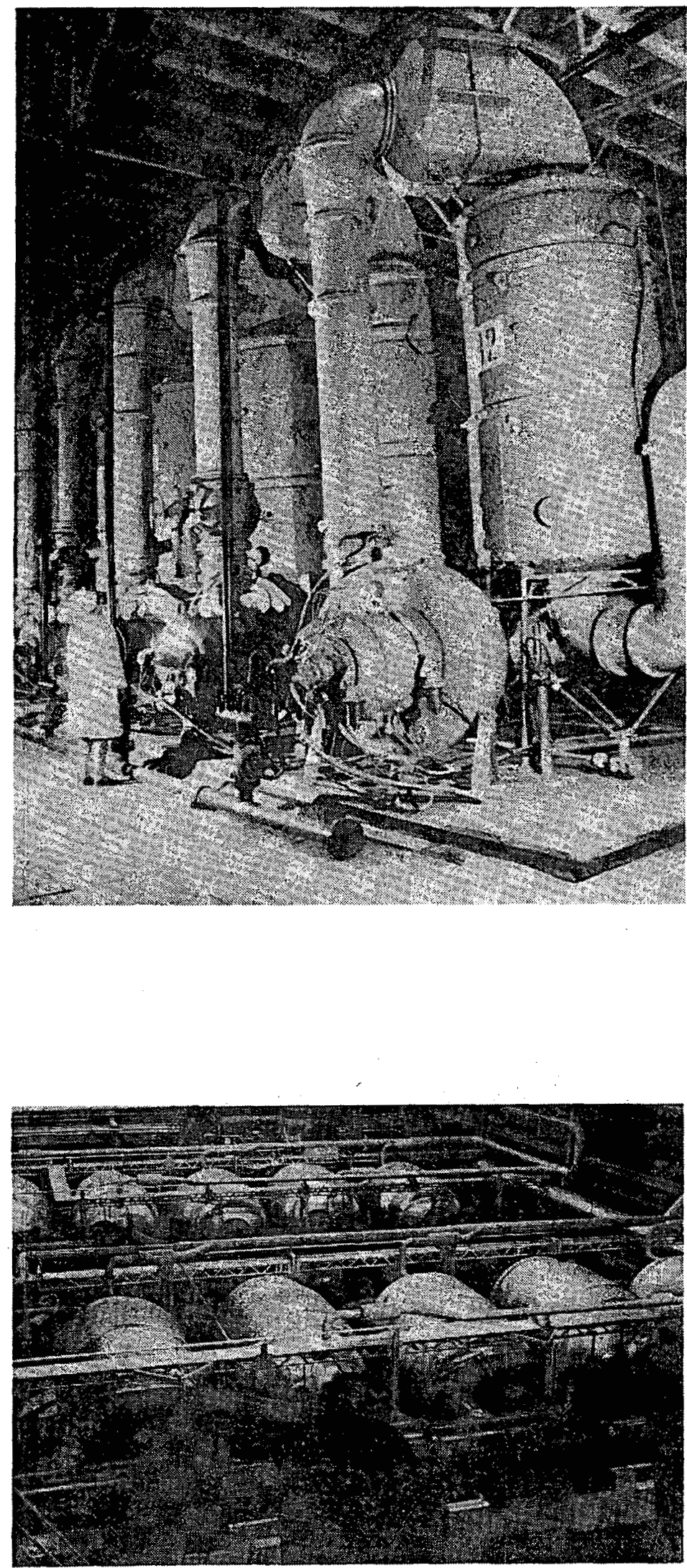

An overview of a portion of a Soviet gaseous diffusion plant.
An overoiew of a portion of a U.S. plant having intermediate size diffusers. The process piping is at the same level as the diffusers, and the overhead piping is part of the cooling system. 
Illustrating a portion of a U.S. plant, eight stages - each of which has a diffuser, a barrier, a motor, a compressor, a heat exchanger, a control valve, and process piping - constitute a cell, the smallest unit of incremental productive capacity that can be added to, or removed from, the operating cascade. Note the cell bypass piping and the cell and bypass block valves.

Other configurations are also possible. These might have different numbers of diffusers in a cell, the diffusers might be vertically oriented with the piping modified accordingly, or there might be separate compressors handling the diffused and undiffused flow.

The elements of an assembly may be mounted horizontally, as is done in the United States, or they may be mounted vertically, as is done in the French diffusion plant at Tricastin (see drawing at right.)
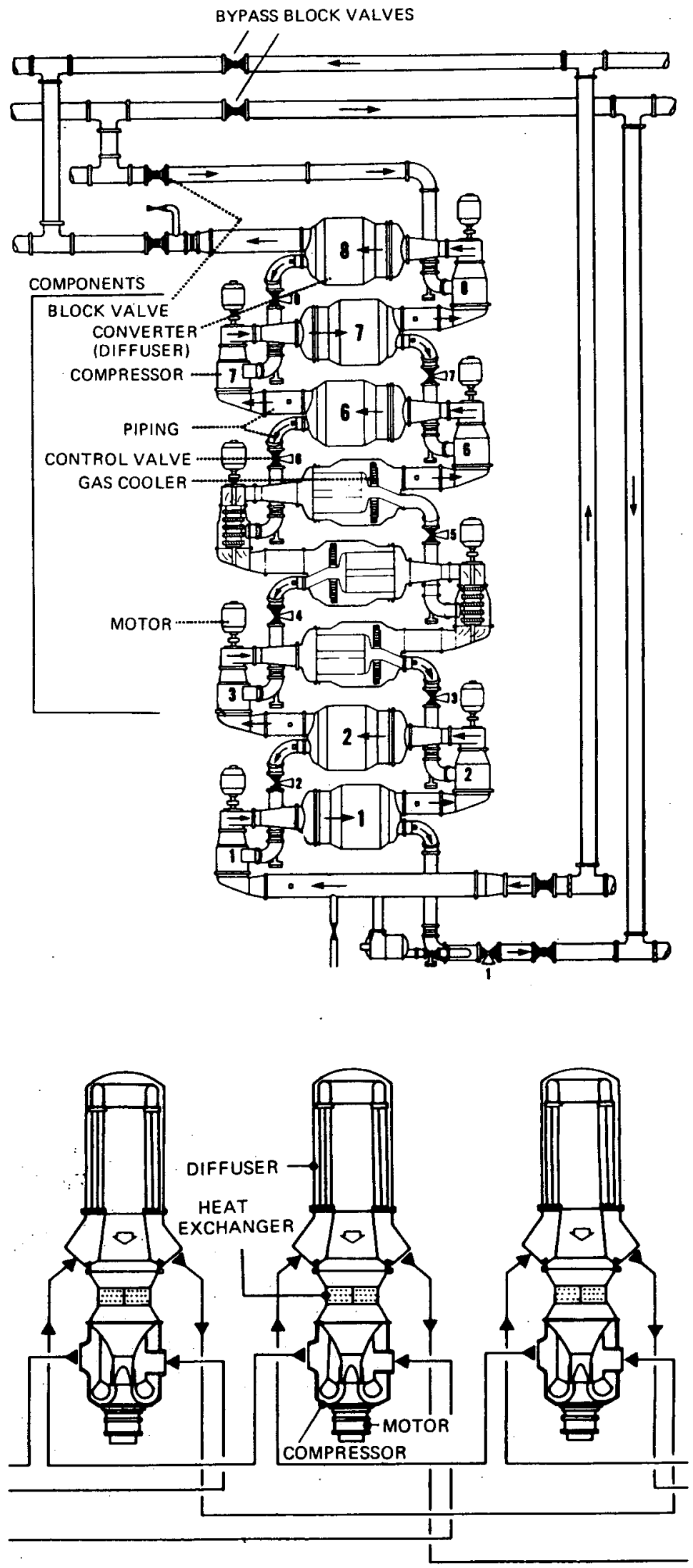


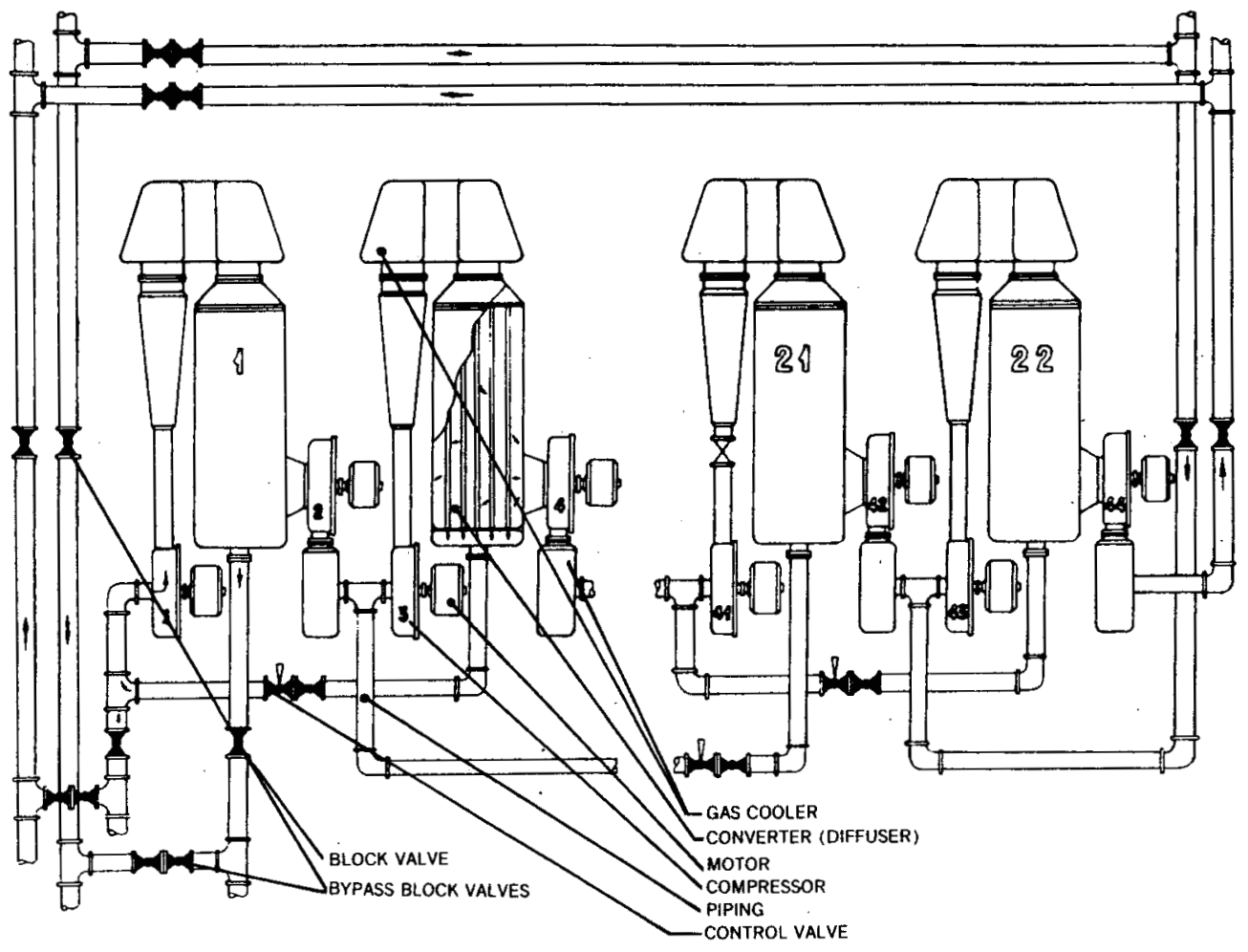

Illustrating a portion of a Soviet plant, twenty-two stages - each

of which has a diffuser, a barrier, two motors, two compressors,

two heat exchangers, a control valve, and process piping -

constitute a cell, the smallest unit of incremental productive

capacity that can be added to, or removed from, the oper-

ating cascade. Note the cell bypass piping and the cell

and bypass block valves. 


\section{DESCRIPTION}

Especially designed or prepared thin, porous filters [with a pore size of 100 to $1000 \AA$, a thickness of $5 \mathrm{~mm}$ (0.20 in.) or less, and for tubular forms, a diameter of $25 \mathrm{~mm}$ (0.98 in.) or less] made of metallic, polymer, or ceramic materials resistant to corrosion by $U F_{6}$, and especially prepared compounds or powders for the manufacture of such filters. Such compounds and powders include nickel or alloys containing $60 \%$ or more nickel, aluminum oxide, or $\mathrm{UF}_{6}{ }^{-}$ resistant fully fluorinated hydrocarbon polymers (having a purity of $99.9 \%$ or more, a particle size less than $10 \mu$, and a high degree of particle size uniformity) that are especially prepared for the manufacture of gaseous diffusion barriers

\section{SPECIAL}

\section{DESIGN FEATURES}

The key to the gaseous diffusion process is the barrier material itself. Good barrier must have a very small pore size and yet a porosity to $\mathrm{UF}_{6}$ as high as possible, a thickness as small as possible, and yet sufficient mechanical strength. Additionally, the barrier must be stable and chemically inert under years of exposure to corrosive $\mathrm{UF}_{6}$ under a strong pressure gradient. 


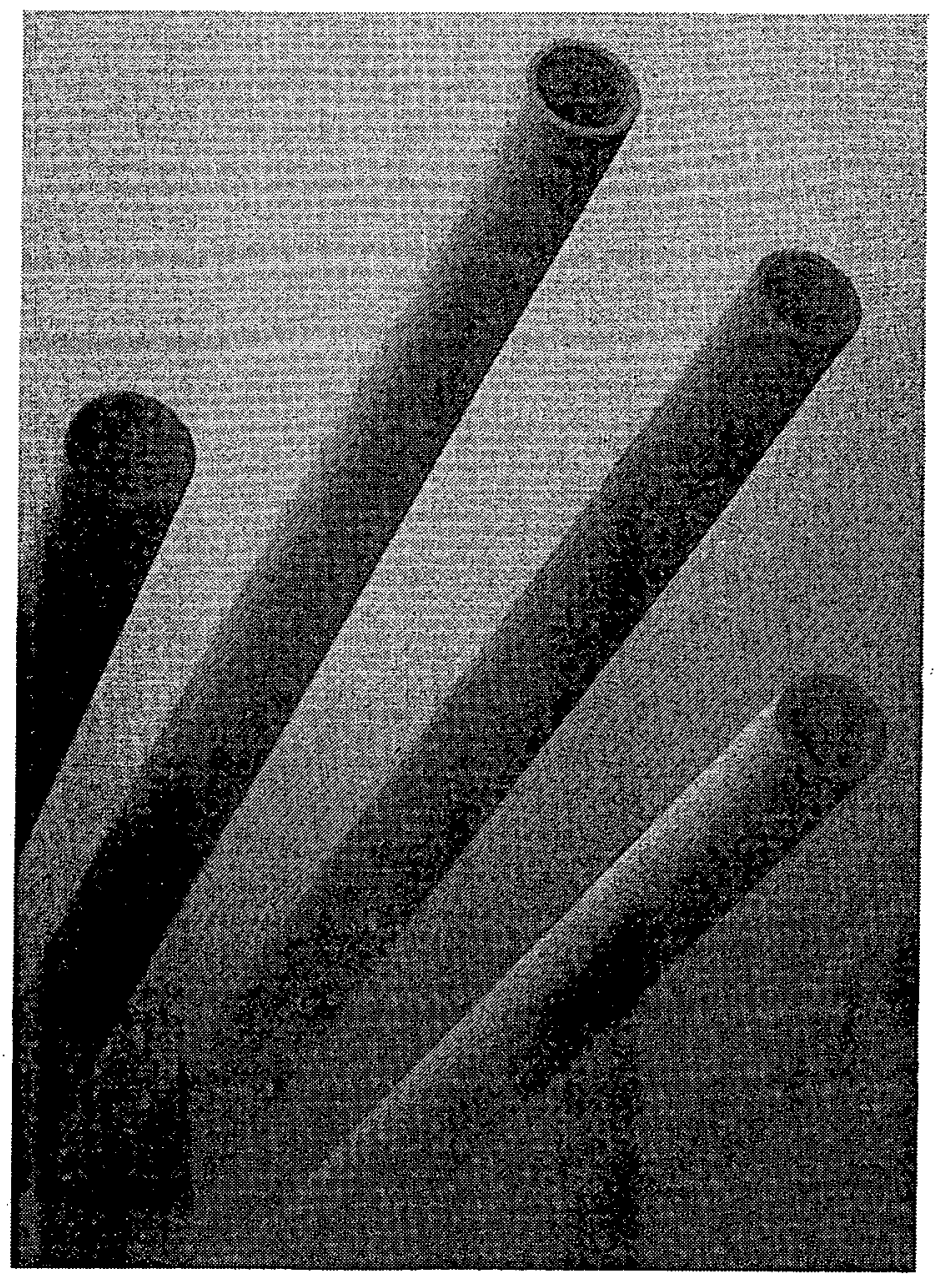

Ceramic barrier used in the French gaseous diffusion plant at Tricastin. Source: Rapport Annuel 1987, Cogema, Washington, D.C., Dec. 31, 1987.

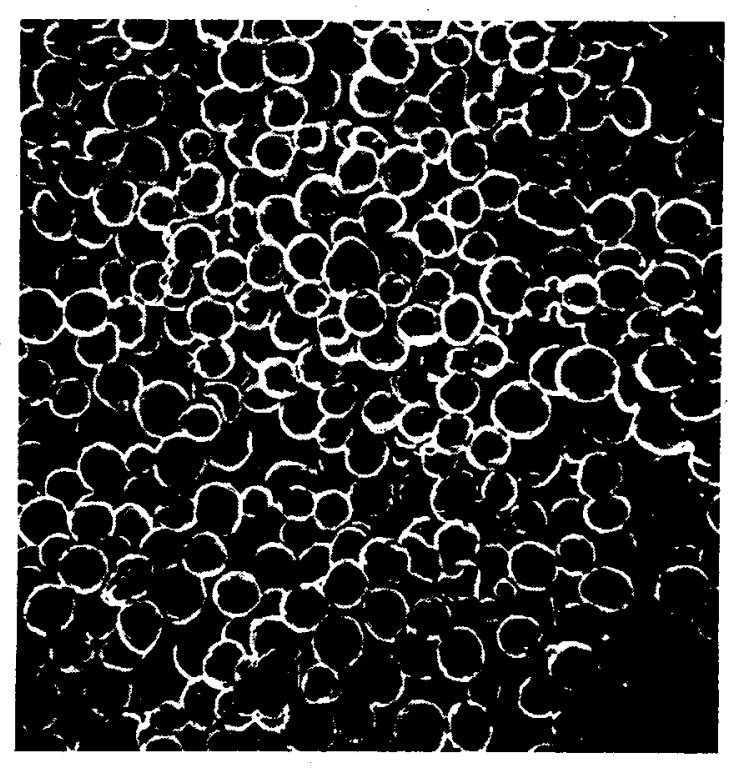

Magnification of barrier material. 
Ceramic barrier used in the Soviet gaseous diffusion plant.

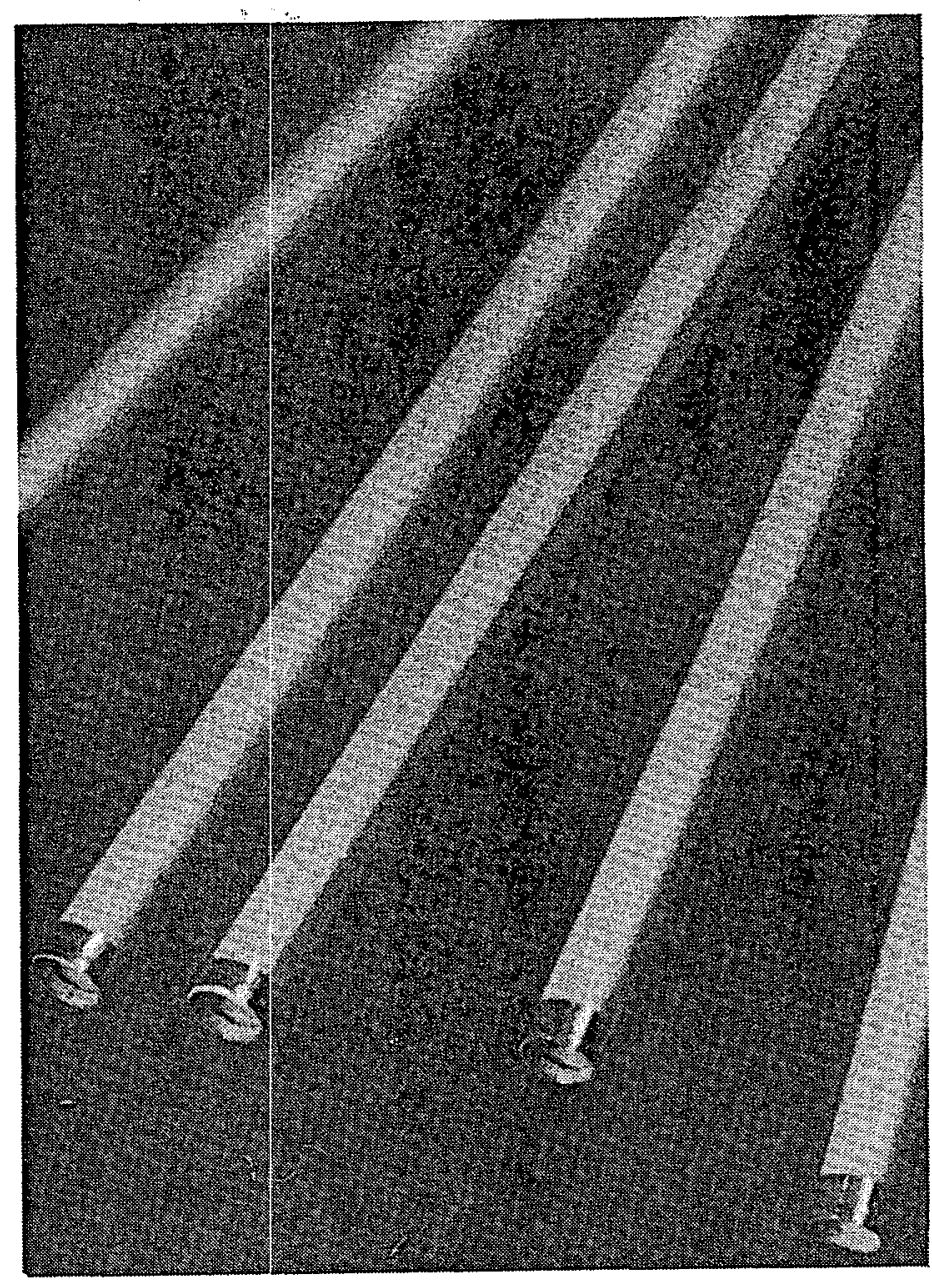

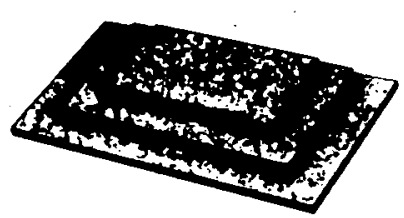

Barrier tubes, disks, and sheets. 
$$
\text { . }
$$ 


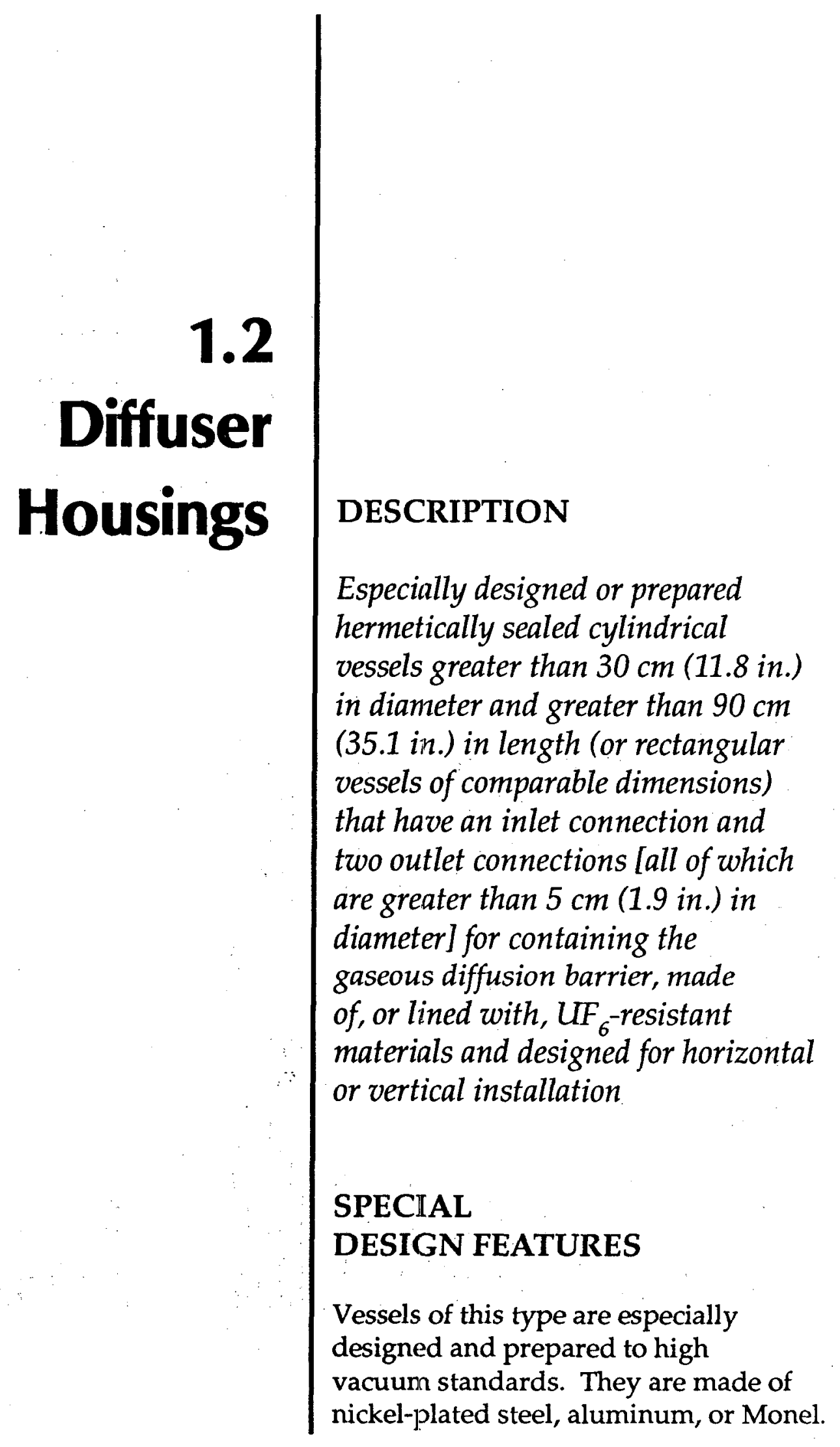



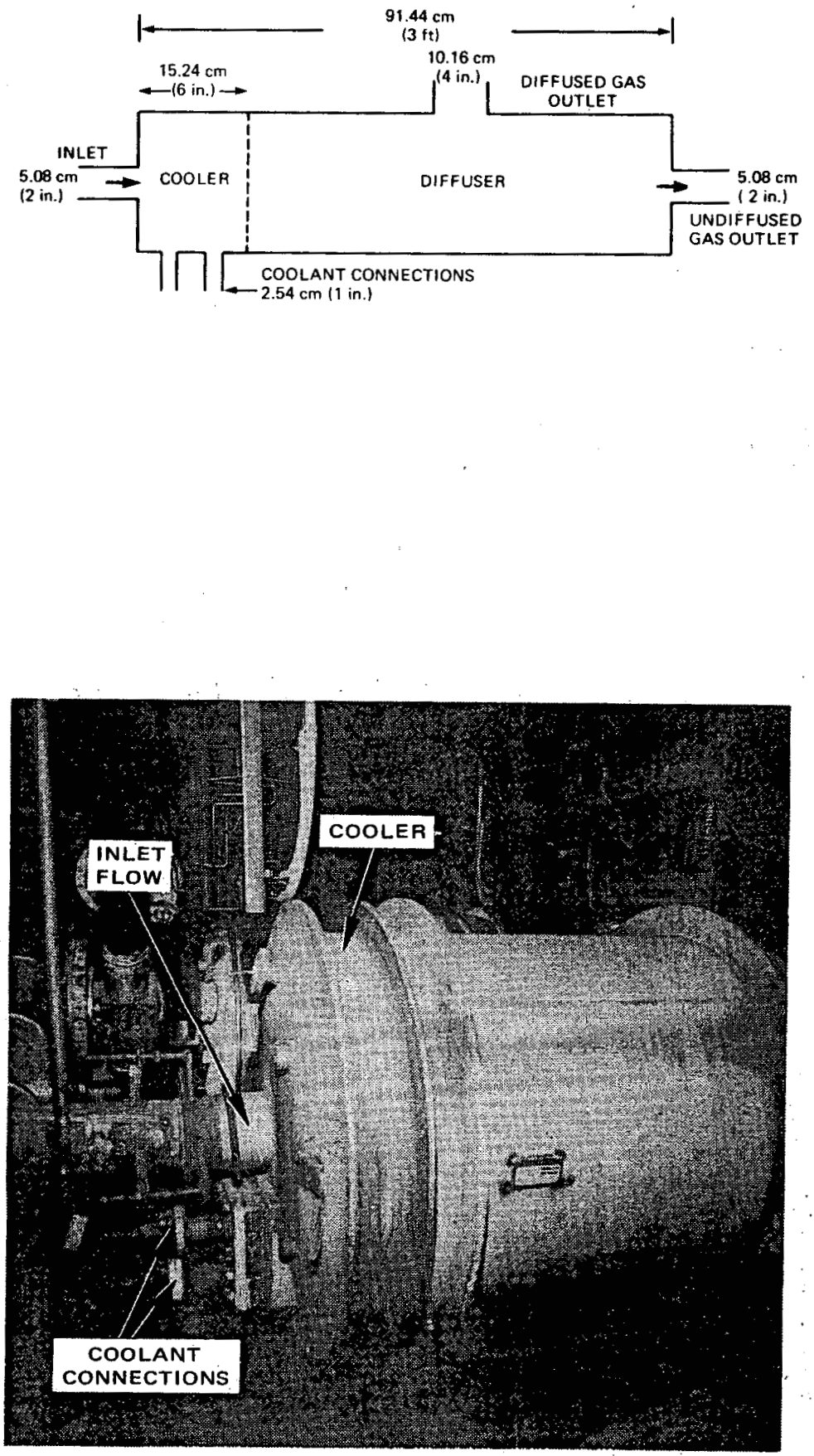

Sketch showing a diffuser housing of the shape (cylindrical) and dimensions that might be expected in a very small diffusion stage. The gas inlet is at the left, the undiffused gas outlet is at the right, and the diffused gas outlet is at the top. Also shown are connections for inlet and outlet flow of coolant. The location of the connection could oary from those shown.
A small U.S. diffuser housing. Note the inlet at the center left and the two coolant connections below it. The section between the two left ridges on the diffuser is the location of the cooler. 
The right end of the diffuser housing in the preceding illustration is shown. The outlet at the center of the housing is for the diffused low-pressure flow; while that above and beyond it is for the high-pressure undiffused flow. The diffused flow is passing into the inlet of a centrifugal compressor in order to be adoanced to the next higher stage. The undiffused flow passes through a control valve (whose stem can be seen) and is blended with the diffused flow from stage two below it.

Interior elements of a large diffuser housing. Here only the diffused gas is cooled at the outlet end of the diffuser housing, while the undiffused gas passes directly to the inlet of the compressor of the next lower stage.
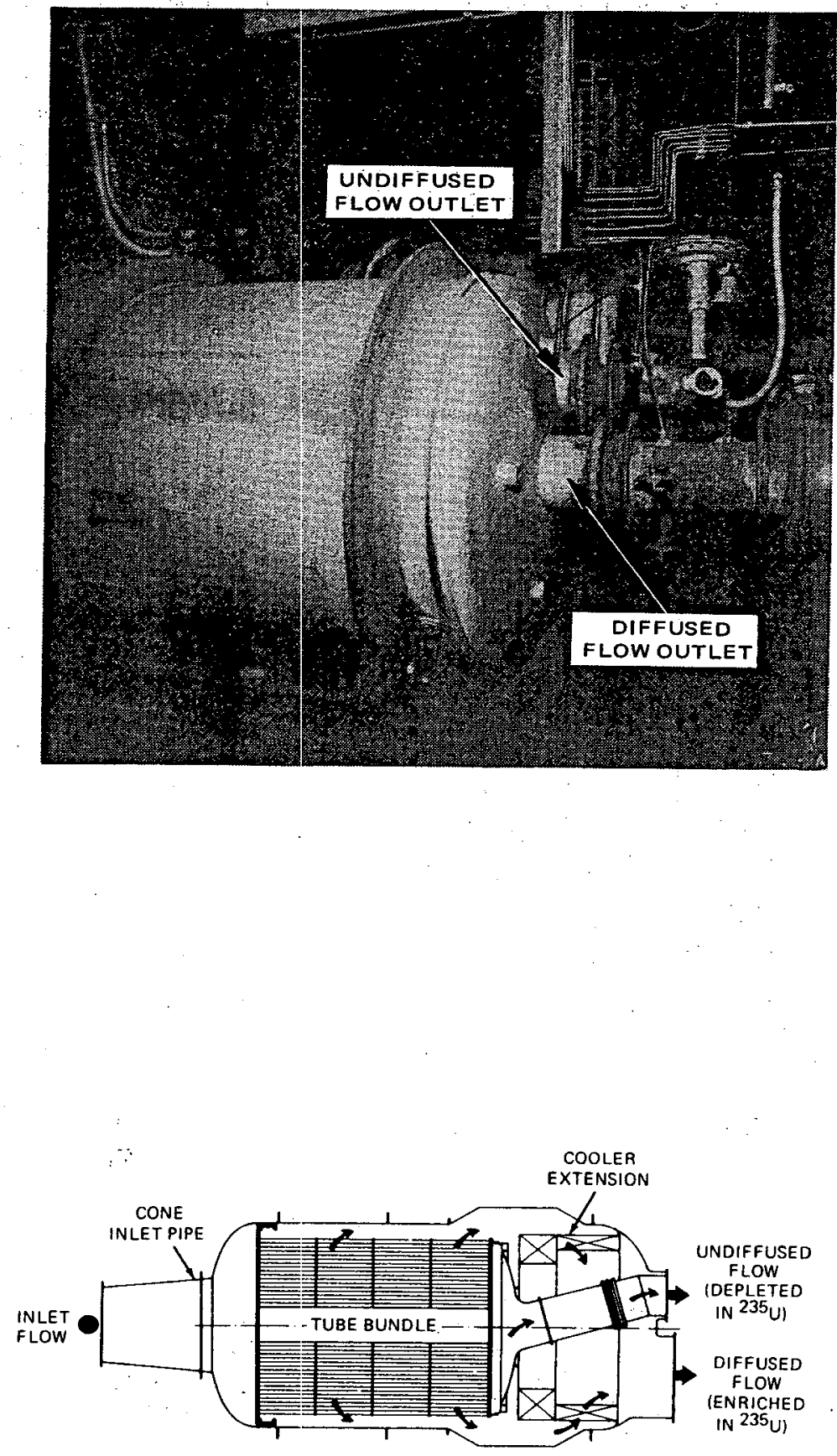


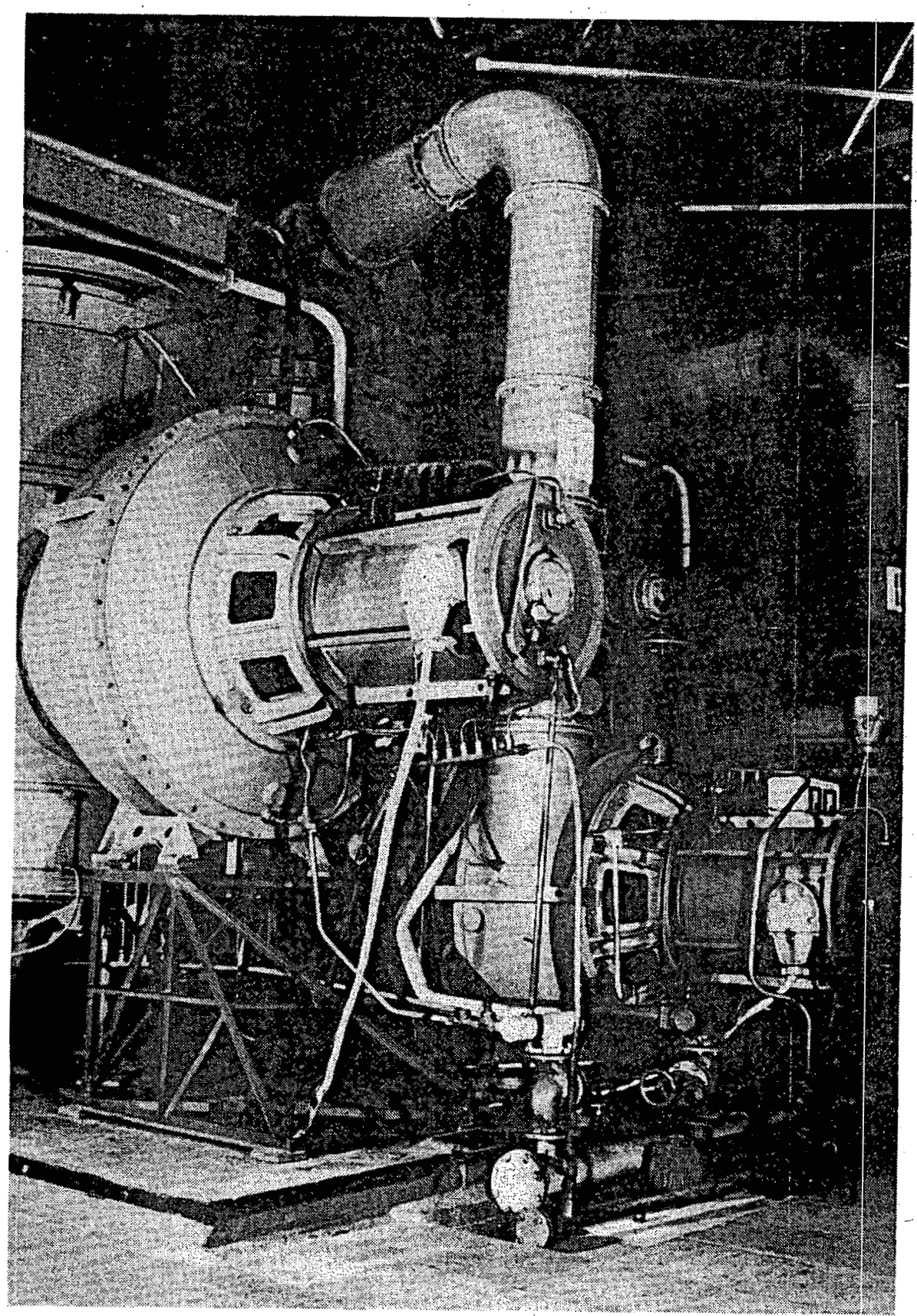

Shown is a diffuser housing for a Soviet gaseous diffusion plant. The gas inlet is at the top; gas flows through the heat exchanger mounted on the diffuser housing. The gas outlet at the right of the housing is for the diffused low-pressure flow, while that below it is for the undiffused high-pressure flow. The diffused flow passes into the inlet of a centrifugal compressor in order to be advanced to the next higher stage. The undiffused flow passes through a control valve and is blended with the diffused flow from the previous stage. 


\section{DESCRIPTION}

Especially designed or prepared axial, centrifugal, or positive displacement compressors or gas blowers with a suction volume capacity of $1 \mathrm{~m}^{3} / \mathrm{min}$ or more of $\mathrm{UF}_{6}$ and with a discharge pressure of up to several hundred $\mathrm{kN} / \mathrm{m}^{2}$ (100 psi), designed for long-term operation in

\section{Compressors}

\section{and Gas Blowers}

the $U F_{6}$ environment with or without an electrical motor of appropriate power, as well as separate assemblies of such compressors and gas blowers. These compressors and gas blowers have a pressure ratio between $2: 1$ and 6:1 and are made of, or lined with, materials resistant to $\mathrm{UF}_{6}$

\section{SPECIAL}

\section{DESIGN FEATURES}

A major feature of these compressors is their materials of construction. Casings may be made of nickel or a high-nickel alloy, or may be plated with one of these materials. Rotor blades and impellers may be made of these materials or of high-strength aluminum alloys. A second requirement is the use of a seal that absolutely precludes leakage between the process system and the atmosphere. For low-flow applications, screw compressors, rotary blowers, or other positive displacement compressors manufactured of the appropriate materials would also be feasible. 

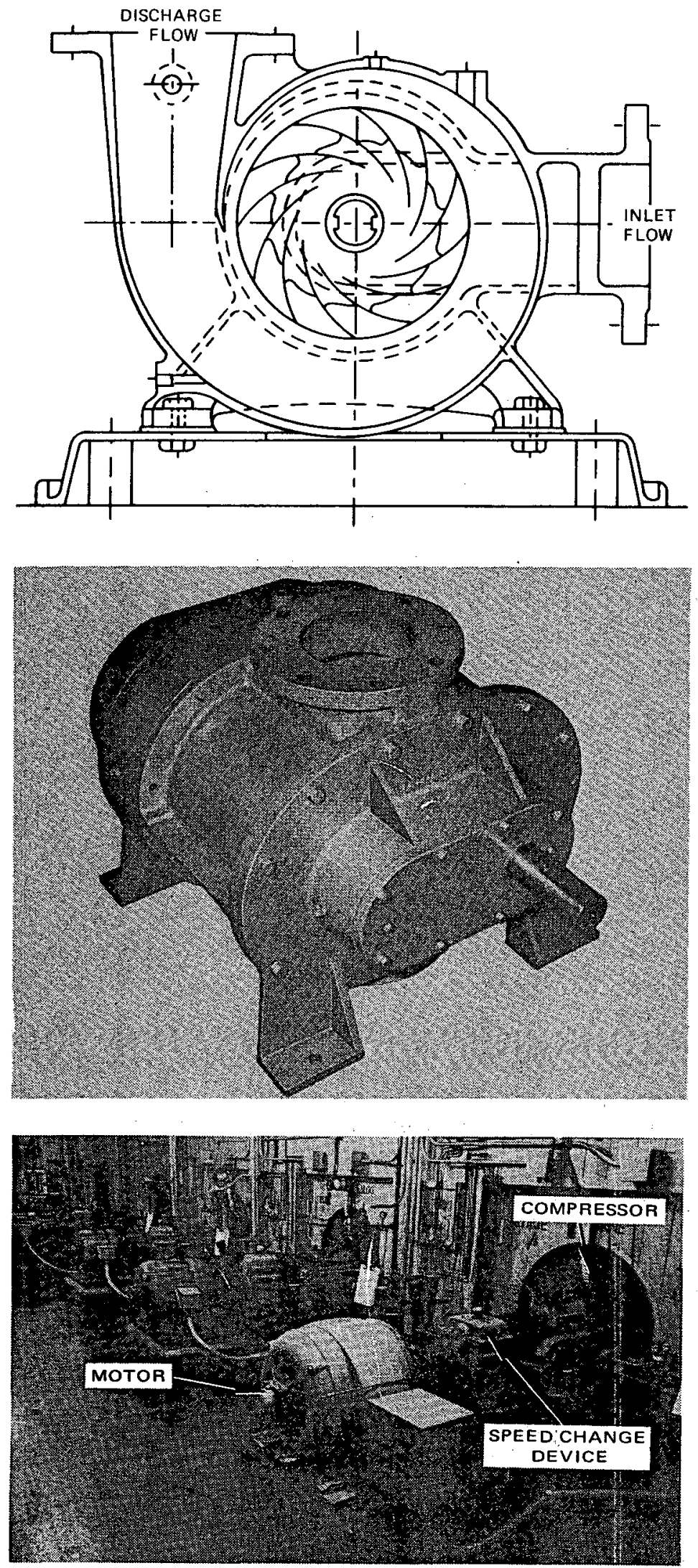

Diagrammatic cross section of a centrifugal gas compressor in the United States. Such a compressor can be mounted with its central drive axis vertical or horizontal. It may also have a diameter as small as $10 \mathrm{~cm}$ (3.9 in.) and operate to accept as little as $1 \mathrm{~m}^{3} / \mathrm{min}$. For UF $_{6}$ service, centrifugal gas compressors must be made of material that resists $U F_{6}$ attack.

Rotary blowers, such as those shown in the photograph and diagram, operate at low volume and horsepower levels. They may have suction volumes between $3 \mathrm{~m}^{3} / \mathrm{min}$ and $30 \mathrm{~m}^{3} / \mathrm{min}$ at $30 \mathrm{hp}$. Their flow connections can be either horiziontal or vertical, and for $U F_{6}$ service they would be built of $U F_{6}$-resistant materials.

A row of centrifugal compressors and associated motors intended for $U F_{6}$ service. These are of an intermediate size among the various ones that have been used in the United States. In this particular array, the compressors were modified to pump a mixture of UF ${ }_{6}$ and nitrogen as part of a cascade used to purge the latter from the former.

The motor shaft connects to a speed'-changing device rather than being coupled directly to the compressor. 


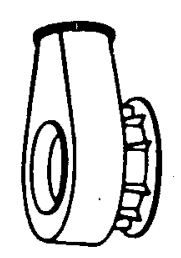

MAIN INLET

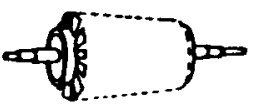

ROTOR-SHAFT

SUBASSEMBLY

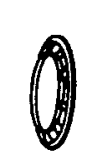

SPIDER

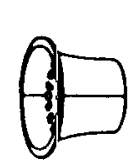

B-STATOR

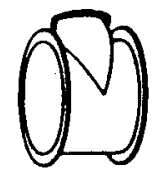

MAIN SHELL AND SIDE INLET NOZZLE

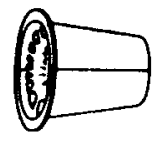

A.STATOR inside the A-stator, spider, and B-stator. The spider serves to guide the gas entering through the side inlet nozzle on an optimal flow path into the B-Section of the compressor. After having passed through this section of the compressor, the full gas flow is discharged through the discharge nozzle.

The internal elements of the rotor and stator sections of a U.S. axial flow compressor. The multiple rows of blades in each section can be seen as well as the large number of blades in each indioidual row of both the stator and the rotor.

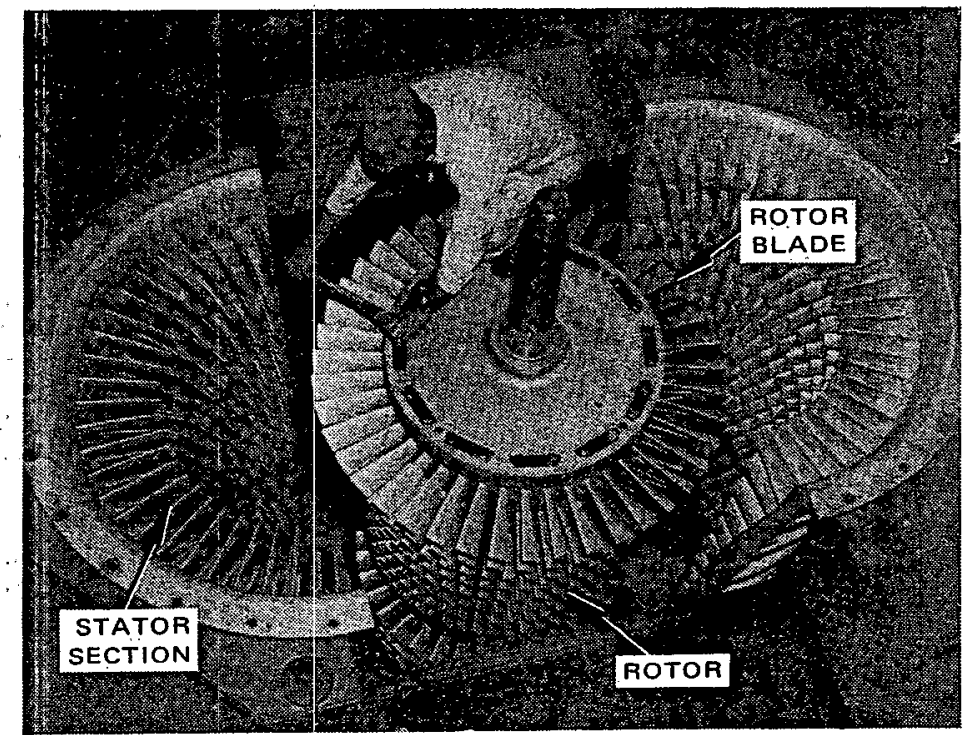


$$
\text { . }
$$ 


\section{DESCRIPTION}

Especially designed or prepared vacuum seals with seal feed and seal exhaust connections for sealing the shaft connecting the compressor or the Rotary gas blower rotor with the driver motor to ensure a reliable seal against inleaking of air into the inner chamber of the compressor or gas blower that is filled with $\mathrm{UF}_{6}$. Such seals are normally designed for a buffer gas inleakage rate of less than $1000 \mathrm{~m}^{3} / \mathrm{min}$

\section{SPECIAL \\ DESIGN FEATURES}

Shaft seals have stringent requirements because $\mathrm{UF}_{6}$ is a toxic, highly reactive material. Neither substantial inleakage of atmospheric gases nor outleakage of $\mathrm{UF}_{6}$ can be tolerated from the thousands of shaft seals operating in a diffusion cascade. Long-term running reliability, adaptability to sealing a wide range of gas pressures, ability to allow transmission of high levels of power, tolerance of cascade pressure disturbances and equipment start/stop cycles, and ease of maintenance are some of the further requirements imposed on economically practical seals. They are wholly made of, or lined with, materials corrosion resistant to $\mathrm{UF}_{6}$. 


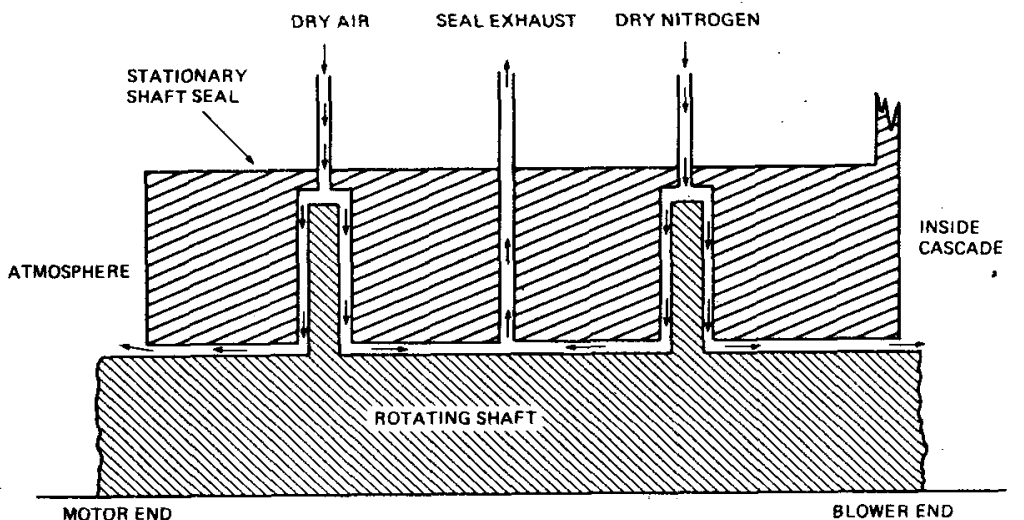

MOTOR END
Representation of the design basis of a rotary shaft seal in the United States. This seal serves to isolate the Process Gas System from the atmosphere where the drive motor is attached to the compressor by means of a rotating shaft. This is accomplished in a viscosity seal of the kind shown by causing gas to flow between the rotating shaft and the stationary shaft seal. On the inner, or process gas, side of the seal, nitrogen flows around the rotating shaft into both the Process Gas System and into a Seal Exhaust System. On the atmosphere, or motor, end of the seal, dry air rather than nitrogen is used, and this flows into both the Seal Exhaust System and out into the atmosphere.

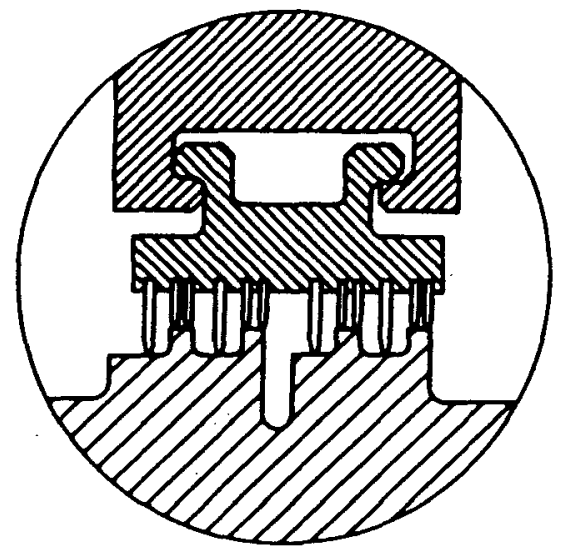

Another type of rotary shaft seal is a labyrinth seal in which there is some transfer of gas between the atmosphere and the Process Gas System, but because of the use of a tortuous flow path, the flow is very small. In the diagram, the upper portion is the stationary element, the lower portion is rotating, and the finger-like contacts between the stationary housing and rotating shaft are the elements of the labyrinth.
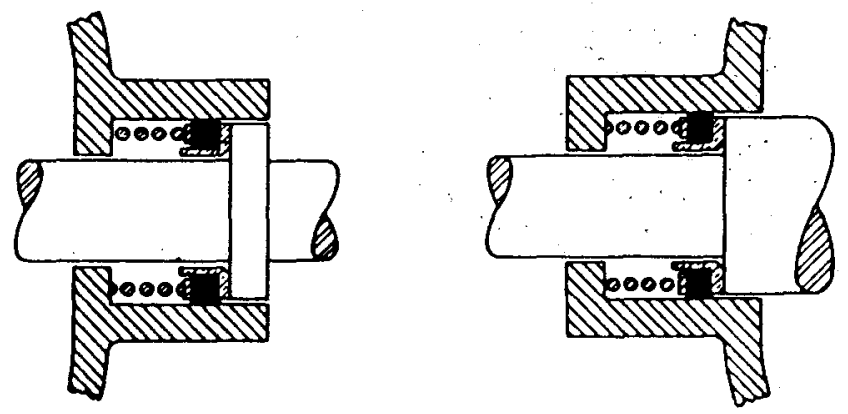

A mechanical shaft seal for application to rotating systems consists of a rotating ring or shoulder attached to the shaft and breaking contact with a flat face at tached to the stationary pump housings. Seals of this sort can be either inside, as on the left, in which the internal pressure tends to tighten the seal, or outside, as on the right, in which the external pressure tightens the seal. 


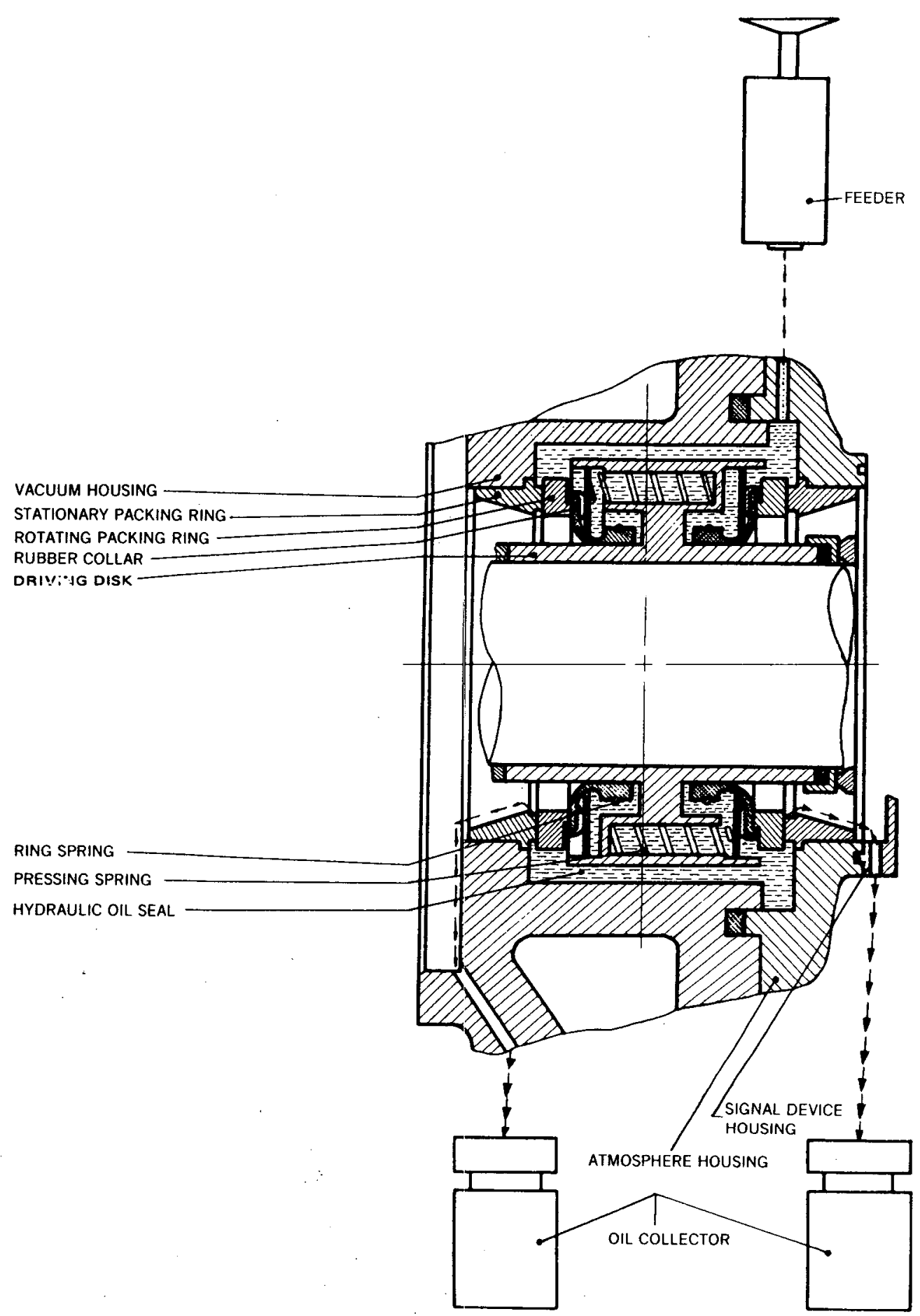

Representation of the design bases of a Soviet rotary shaft seal. This seal serves to isolate the Process Gas System from the atmosphere where the drive motor is attached to the compressor by means of a rotating shaft. Isolation is achieved by a hydraulic oil seal, two pairs of contacting rings, out leakages from which are compensated for by oil from the feeder. Oil used would be UF ${ }_{6}$ resistant. 
$$
\text { . }
$$ 


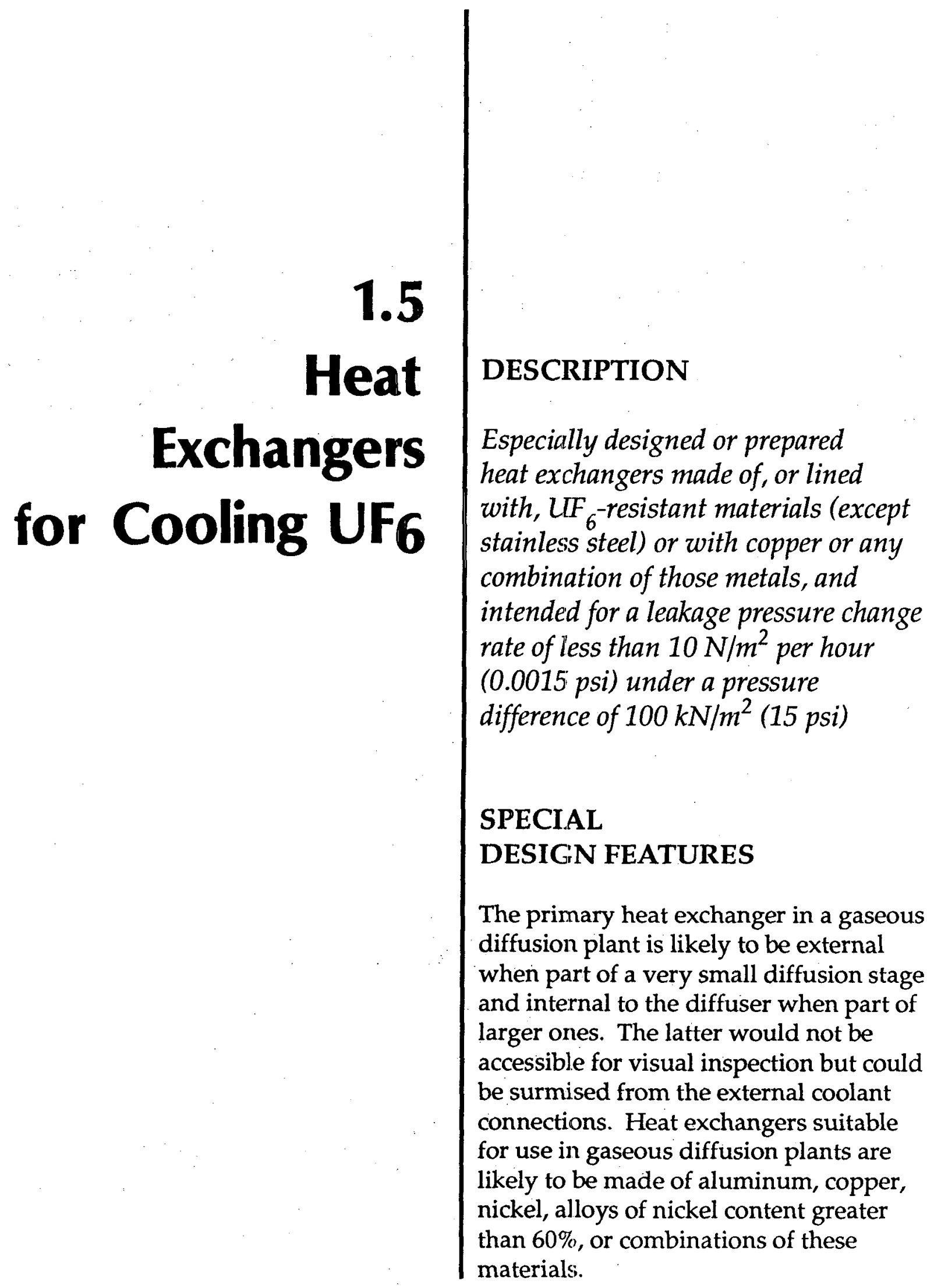



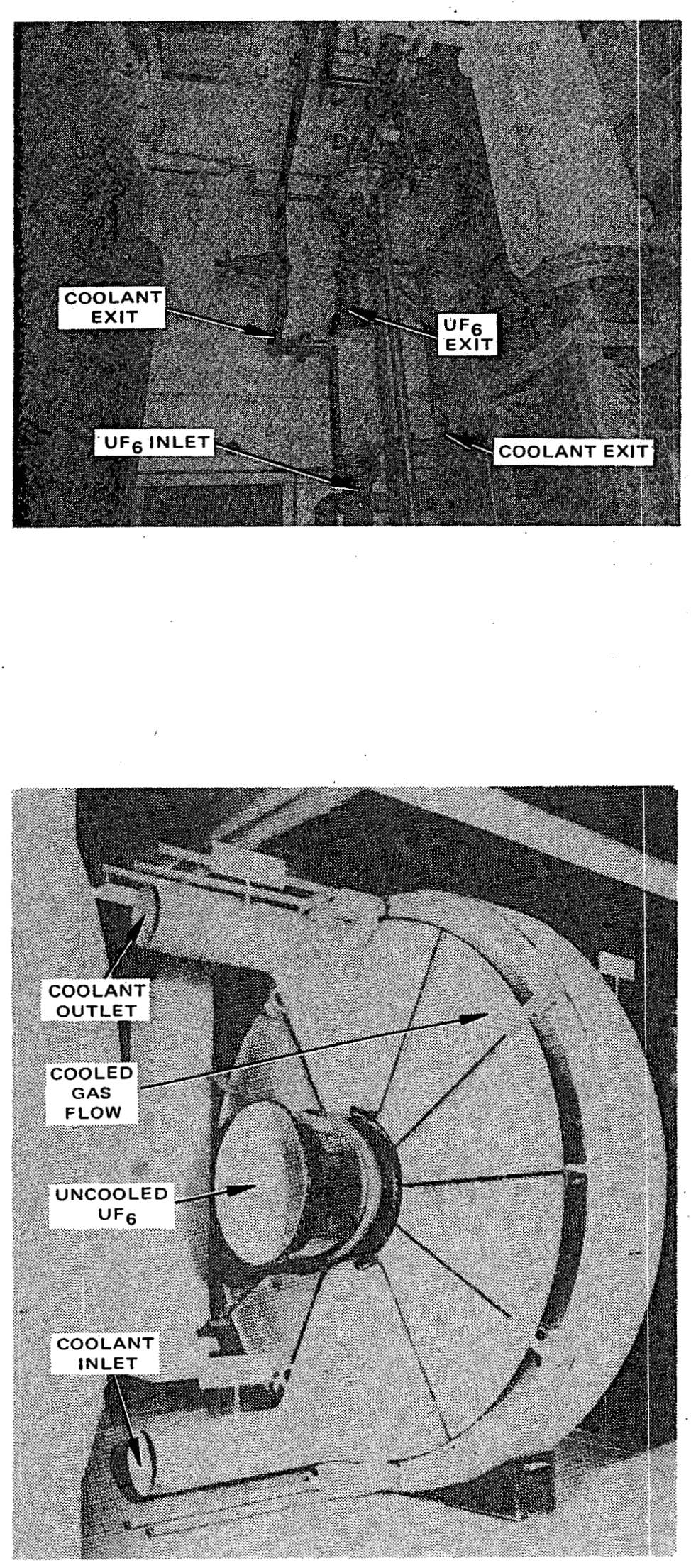

A small heat exchanger in service in a U.S. pilot plant used for testing equipment. The heat exchanger is in the center of the photograph and has UF flowing upward through it. The coolant flow is counter to that of the UF ${ }_{6}$ entering the heat exchanger at the upper left and leaving it at the lower right. A portion of a second heat exchanger can be seen at the upper right. Such heat exchangers may have process line diameters of $5 \mathrm{~cm}$ (1.9 in.) or greater and have very stringent leak rate requirements.
A large heat exchanger in service in the largest U.S. gaseous diffusion stages. The heat exchanger, or gas cooler, is in the shape of a large flat disk; the process gas flows axially through the disk, and the coolant flows through circumferential coils. In other heat exchanger designs, the process gas flows radially inward over the coolant coils. 


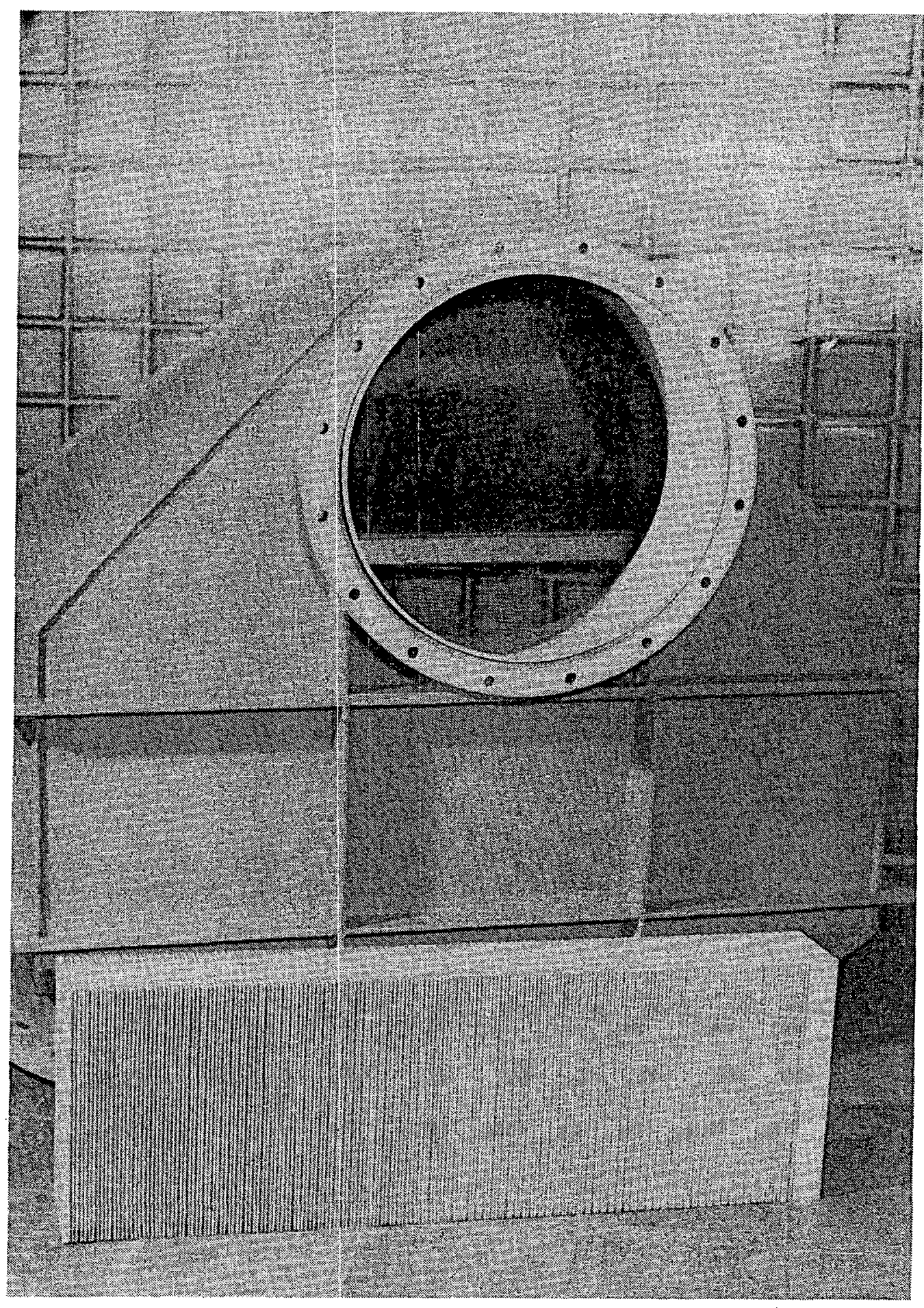

A heat exchanger for cooling $U F_{6}$ and cooling section of a Soviet gaseous diffusion plant. The heat exchanger includes steel housing enclosing an assembly of aluminum sections. The latter is made in the ribbed form. Gas flows between ribs. The coolant flows through the section coils. 


\section{DESCRIPTION \\ Especially designed or prepared \\ auxiliary systems, equipment, and \\ components for use in gaseous \\ diffusion enrichment plants \\ SPECIAL \\ DESIGN FEATURES}

2.

The auxiliary systems, equipment, and components for gaseous diffusion enrichment plants are the systems of plants needed to feed UF ${ }_{6}$ to the gaseous diffusion assembly, to link the individual assemblies to each other, to form cascades (or stages) to allow for progressively higher enrichments, and to extract the "product" and "tails" UF 6 from the technological process. Because of the high inertial properties of diffusion cacades, any interruption in their operation, and especially their shutdown, leads to serious consequences. Therefore a strict and constant maintenance of vacuum in all technological systems, automatic protection from accidents, and precise automated regulation of the gas flow is of importance in a gaseous diffusion plant. All this leads to a need to equip the plant with a large number of special measuring, regulating, and controlling systems.

Normally $\mathrm{UF}_{6}$ is evaporated from cylinders placed within autoclaves and is distributed in gaseous form to the entry point by way of cascade header pipework. The "product" and "tails" UF 6 gaseous streams flowing from exit points are passed by way of cascade header pipework either to cold traps or to compression stations where the UF 6 gas is liquified prior to onward transfer into suitable containers for transportation or storage. Because a gaseous diffusion enrichment plant consists of a large number of gaseous diffusion assemblies arranged in cascades, there are many kilometers of cascade header pipework incorporating thousands of welds with a substantial amount of repetition of layout. The equipment, components, and piping systems are fabricated to very high vacuum and cleanliness standards.

The following items either come into direct contact with the UF 6 process gas or directly control the flow within the cascade. All surfaces that come into contact with the process gas are wholly made of, or lined with, $\mathrm{UF}_{6}$-resistant materials. 


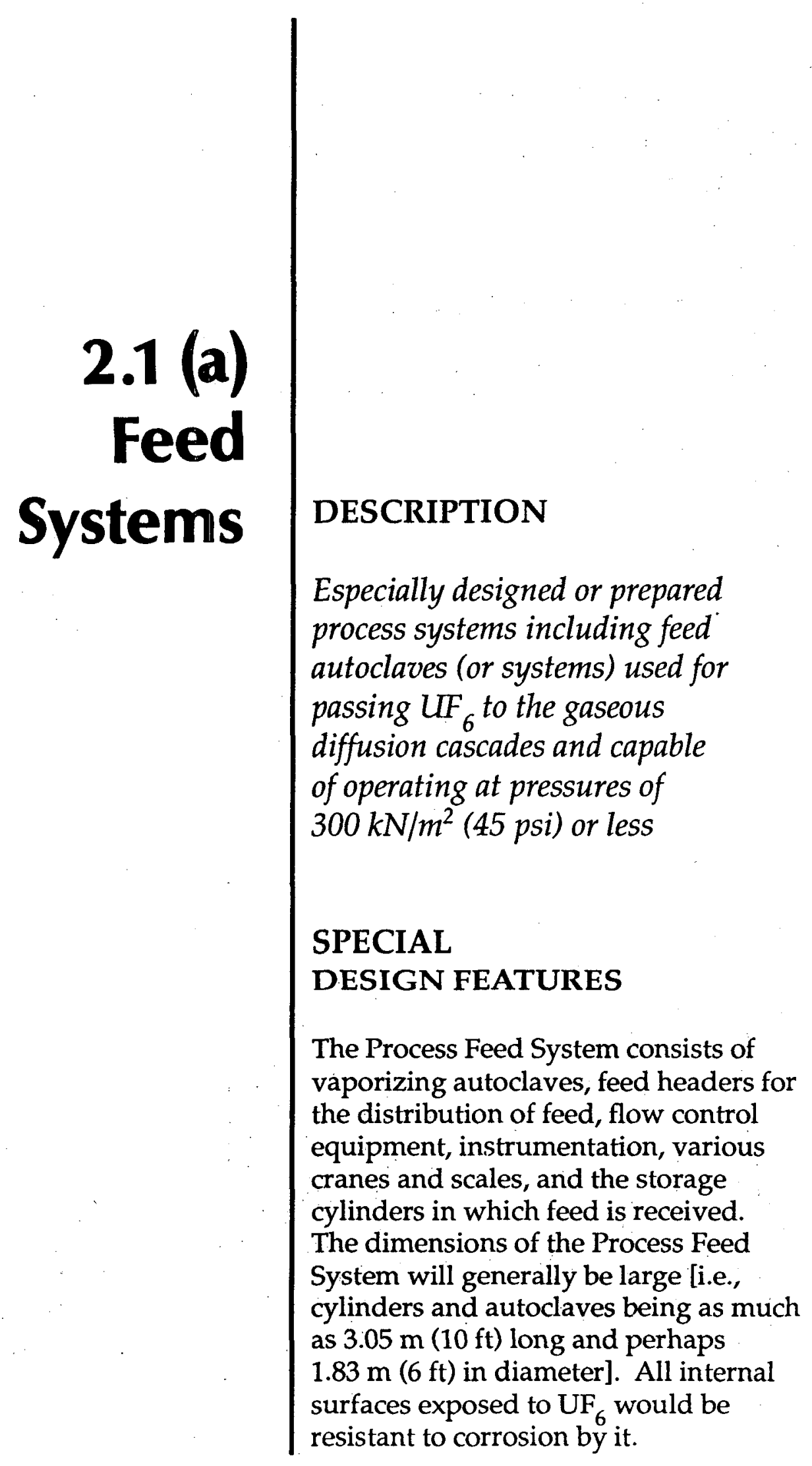



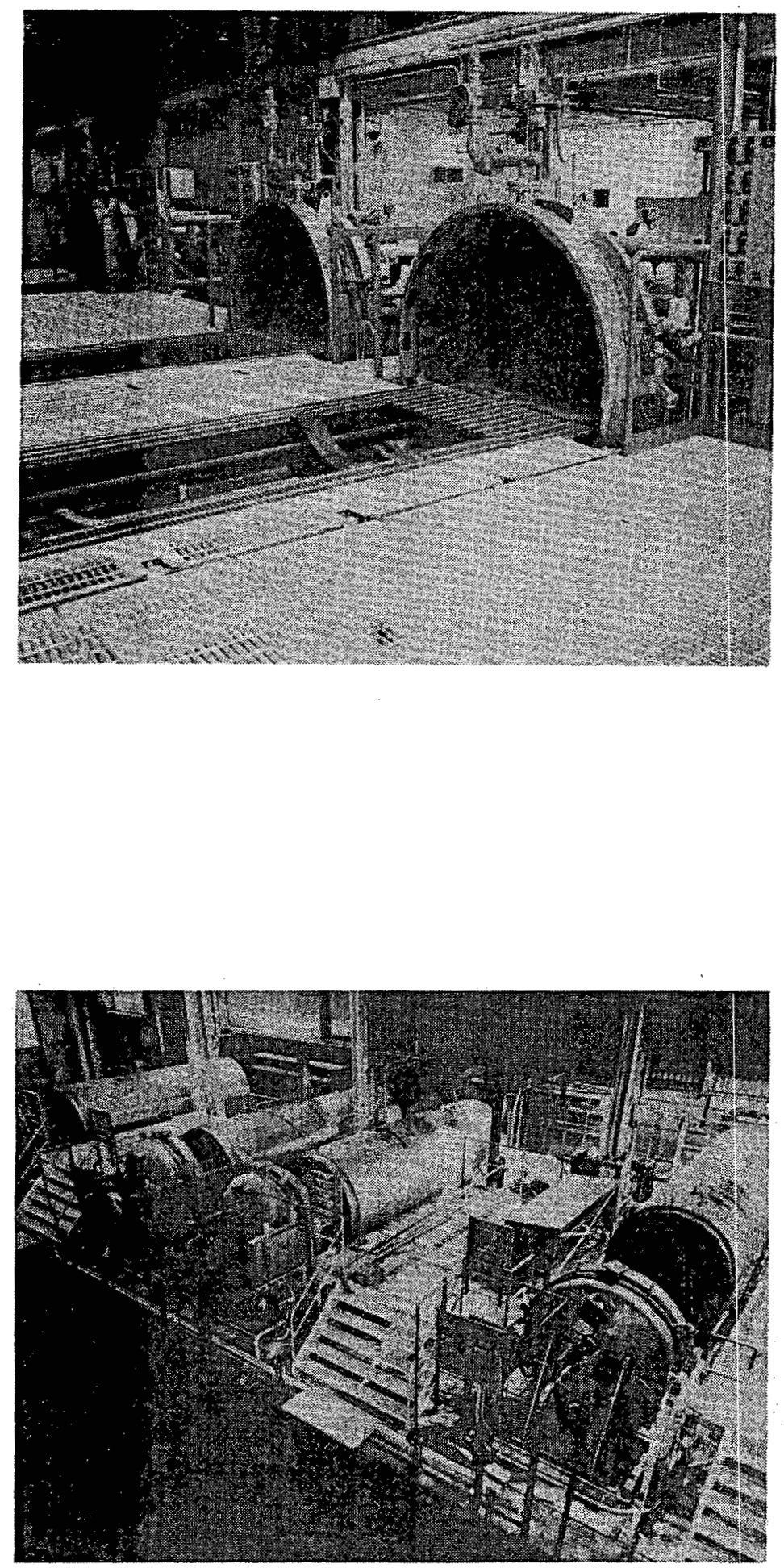

Two U.S. autoclaves ready to receive cylinders of liquid $U F_{6}$. The cylinders are placed in the recessed openings opposite the dished heads. Note the complexity of piping and controls necessary to operate a facility of this kind.

A more general view of the autoclaves in the feed vaporization area of a feed and withdrawal facility. A number of autoclaves can be seen with the autoclave cover in place over the cylinder position. 
This U.S. cylinder is of a nominal 2-1/2-ton capacity and is used for storing and transporting $U F_{6}$. As is indicated in the table of specifications, it may be used at ${ }^{235} U$ concentrations of up to $5 \%$. Such a cylinder can also be used in $U F_{6}$ withdrawal and storage operations.

\section{NOMINAL 2-1/2-TON CYLINDEA}

\begin{tabular}{ll}
\hline Nominal diameter & $0.76 \mathrm{~m}$ \\
Nominal length & $2.05 \mathrm{~m}$ \\
Wall thickness & $1.3 \mathrm{~cm}$ \\
Nominal tare weight & $635 \mathrm{~kg}(1400 \mathrm{lb})$ \\
Maximum net weight & $2277 \mathrm{~kg}(5020 \mathrm{lb})$ \\
Nominal gross weight & $2912 \mathrm{~kg}(6420 \mathrm{lb})$ \\
Minimum volume & $736 \mathrm{~L}\left(26 \mathrm{ft}^{3}\right)$ \\
Basic material of construction & $S t e e l$ \\
Service pressure & $1380 \mathrm{kPa}$ \\
Hydrostatic test pressure & $2760 \mathrm{kPa}$ \\
Isotopic content limit & $5 \% 235 \mathrm{U}$
\end{tabular}

Valve used: 1 -in. valve.

Other configurations including vertical designs also exist, and capacities can be as much as $100,000 \mathrm{~kg}$.

\section{NOMINAL 10-TON CYLINDER}

\begin{tabular}{ll}
\hline Nominal diameter & $1.22 \mathrm{~m}$ \\
Nominal length' & $3.07 \mathrm{~m}$ \\
Wall thickness & $16 \mathrm{~mm}$ \\
Nominal tare weight & $2041 \mathrm{~kg}(4500 \mathrm{lb})$ \\
Maximum net weight & $9539 \mathrm{~kg}(21,030 \mathrm{lb})$ \\
Nominal gross weight & $11,580 \mathrm{~kg}(25,530 \mathrm{lb})$ \\
Minimum volume & $3.085 \mathrm{~m}^{3}\left(108.9 \mathrm{ft}^{3}\right)$ \\
Basic material of construction & $S t e e l$ \\
Service pressure & $1380 \mathrm{kPa}$ \\
Hydrostatic test pressure & $2760 \mathrm{kPa}$ \\
Isotopic content limit & $4.5 \% 235 \mathrm{U}$ max. with \\
& moderation control \\
\hline
\end{tabular}

Valve used: 1 -in. valve.

\section{NOMINAL 14-TON CYLINDER}

Nominal diameter

Nominal length

Wall thickness

Nominal tare weight

Maximum net weight

Nominal gross weight

Minimum volume

Basic material of construction

Service pressure

Hydrostatic test pressure

Isotopic content limit
$1.22 \mathrm{~m}$

$3.81 \mathrm{~m}$

$16 \mathrm{~mm}$

$2359 \mathrm{~kg}(5200 \mathrm{lb})$

$12,501 . \mathrm{kg}(27,560 \mathrm{lb})$

$14,860 \mathrm{~kg}(32,760 \mathrm{lb})$

$4.04 \mathrm{~m}^{3}\left(142.7 \mathrm{ft}^{3}\right)$

Steel

$1380 \mathrm{kPa}$

$2760 \mathrm{kPa}$

$4.5 \%{ }^{235} \mathrm{U}$ max. with

moderation control
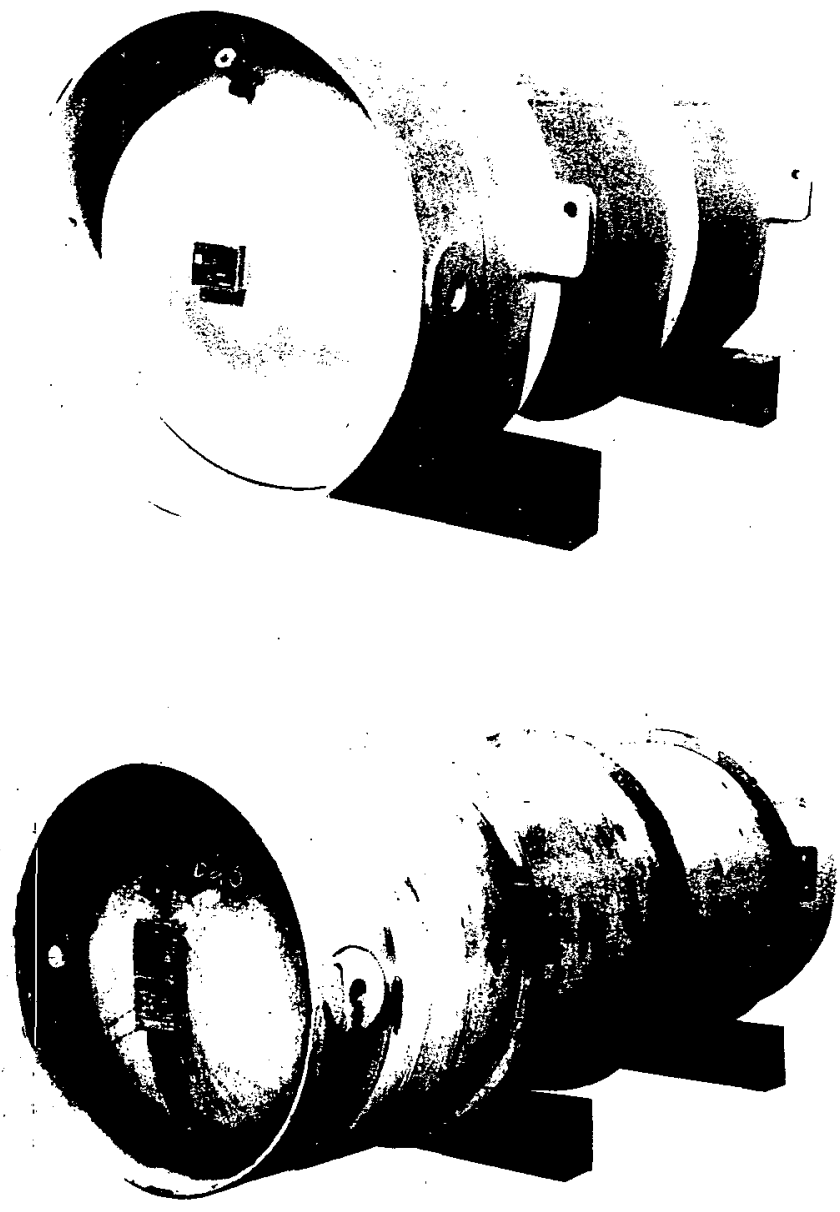

Valve used: 1 -in. valve. 


\section{1 (b) Product and Tails Withdrawal Systems}

\section{DESCRIPTION}

Desublimers (or cold traps) used to remove $U_{F}$ from diffusion cascades. Liquefaction stations where UF ${ }_{6}$ gas from the cascade is compressed and cooled to form liquid UF IF $_{\text {. Product }}$ and tails stations for transferring UF $_{6}$ into containers suitable for shipping, storage, or other uses. These especially designed or prepared process systems are capable of operating at pressures of $300 \mathrm{kN} / \mathrm{m}^{2}(45 \mathrm{psi})$ or less

\section{SPECIAL DESIGN FEATURES}

For low ${ }^{235} \mathrm{U}$ assays, the Product Withdrawal System may consist of a compression liquefaction cycle in which $\mathrm{UF}_{6}$ is compressed to above the triple-point pressure and cooled in a gas cooler. For higher assays and presumably lower product rates, refrigerated cold traps could be used. The Tails Withdrawal System may also operate on a compression liquefaction cycle or may have a cold trap cooled with chilled water or brine in which $\mathrm{UF}_{6}$ is desublimed for isolation before vaporization into a collection cylinder. All internal surfaces in contact with $\mathrm{UF}_{6}$ in these systems must be made of materials resistant to $\mathrm{UF}_{6}$ (i.e., nickel, high-nickel alloys, aluminum, or copper). This equipment will generally be large - of the order of $1 \mathrm{~m}(3.3 \mathrm{ft})$ in diameter when insulated and 2 or $3 \mathrm{~m}$ ( 6.6 or $9.8 \mathrm{ft}$ ) long. Also, a product system designed to handle highly enriched uranium will have had geometric constraints imposed on it. Specifically, cylindrical vessels will be no more than $12.5 \mathrm{~cm}$ (4.9 in.) in diameter. Boron alloys may also be present; these serve as neutron absorbers and preclude the possibility of a critical nuclear reaction. 

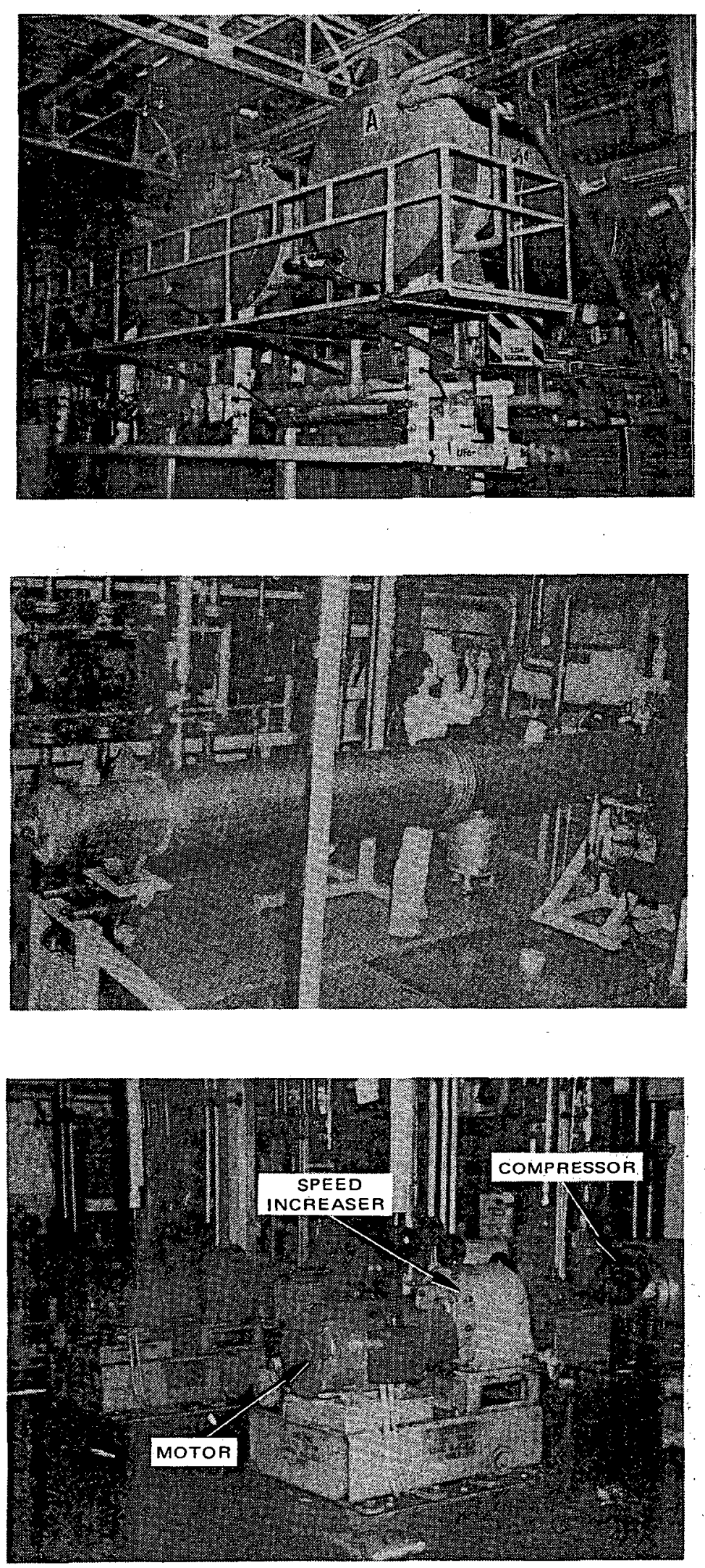

Cold traps shown in the elevated area are used in the United States to remooe cascade tails from the Process System. Tails so removed are then transferred to large storage cylinders. Such cold traps are operated with chilled water for the condensation step and then with heated water for the subsequent oolatilization. The use of water in such low-assay UIF ${ }_{6}$ systems is permissible.
View of an uninsulated cold trap functioning as part of a Product Withdrawal System. Although such a cold trap would ordinarily be used for removing either tails or operating inventory from a cascade, it could also be used for product removal.
Motor drive speed increaser and compressor for a typical U.S. compression-liquefaction station. 
The sampling cylinder including the attached valve shown is one used in the United States to collect UF ${ }_{6}$ at high${ }^{235} U$-assay levels. The special feat ures for the cylinder indicate a capacity of slightly over $2.2 \mathrm{~kg}(4.8 \mathrm{lb})$ of $U F_{6}$.

\section{GENERAL DATA}

\begin{tabular}{ll}
\hline Nominal diameter & $9 \mathrm{~cm}$ \\
Nominal length & $29 \mathrm{~cm}$ \\
Wall thickness & $3.0 \mathrm{~mm}$ \\
Nominal tare weight & $1.91 \mathrm{~kg}(4.2 \mathrm{lb})$ \\
Maximum net weight & $2.22 \mathrm{~kg}(4.9 \mathrm{lb})$ \\
Nominal gross weight & $4.13 \mathrm{~kg}(9.1 \mathrm{lb})$ \\
Minimum volume & $736 \mathrm{~cm}^{3}\left(0.026 \mathrm{ft}^{3}\right)$ \\
Basic material of construction & $\mathrm{Nickel}$ \\
Service pressure & $1380 \mathrm{kPa}$ \\
Hydrostatic test pressure & $2760 \mathrm{kPa}$ \\
Isotopic content limit & $100 \%{ }^{235} \mathrm{U}$ max. \\
\hline
\end{tabular}

The product cylinder shown is used in the United States to collect $U F_{6}$ at high- ${ }^{235} U$ assay levels. The connections permit $U_{F_{6}}$ to be passed through the cylinder while the product is being frozen out. Such a cylinder has a capacity of about $25 \mathrm{~kg}$

(55.1 lb).

GENERAL DATA

\begin{tabular}{ll}
\hline Nominal diameter & $12.7 \mathrm{~cm}$ \\
Nominal length & $91 \mathrm{~cm}$ \\
Wall thickness & $6.4 \mathrm{~mm}$ \\
Nominal tare weight & $24.95 \mathrm{~kg}(55 \mathrm{lb})$ \\
Maximum net weight & $24.95 \mathrm{~kg} \mathrm{(55} \mathrm{lb)}$ \\
Nominal gross weight & $49.9 \mathrm{~kg}(110 \mathrm{lb})$ \\
& (without cap) \\
Minimum volume & $8.4 \mathrm{~L}\left(0.284 \mathrm{ft}^{3}\right)$ \\
Basic material of construction & Monel \\
Service pressure & $1380 \mathrm{kPa}$ \\
Hydrostatic test pressure & $2760 \mathrm{kPa}$ \\
Isotopic content limit & $100 \% 235 \mathrm{U}$ max.
\end{tabular}
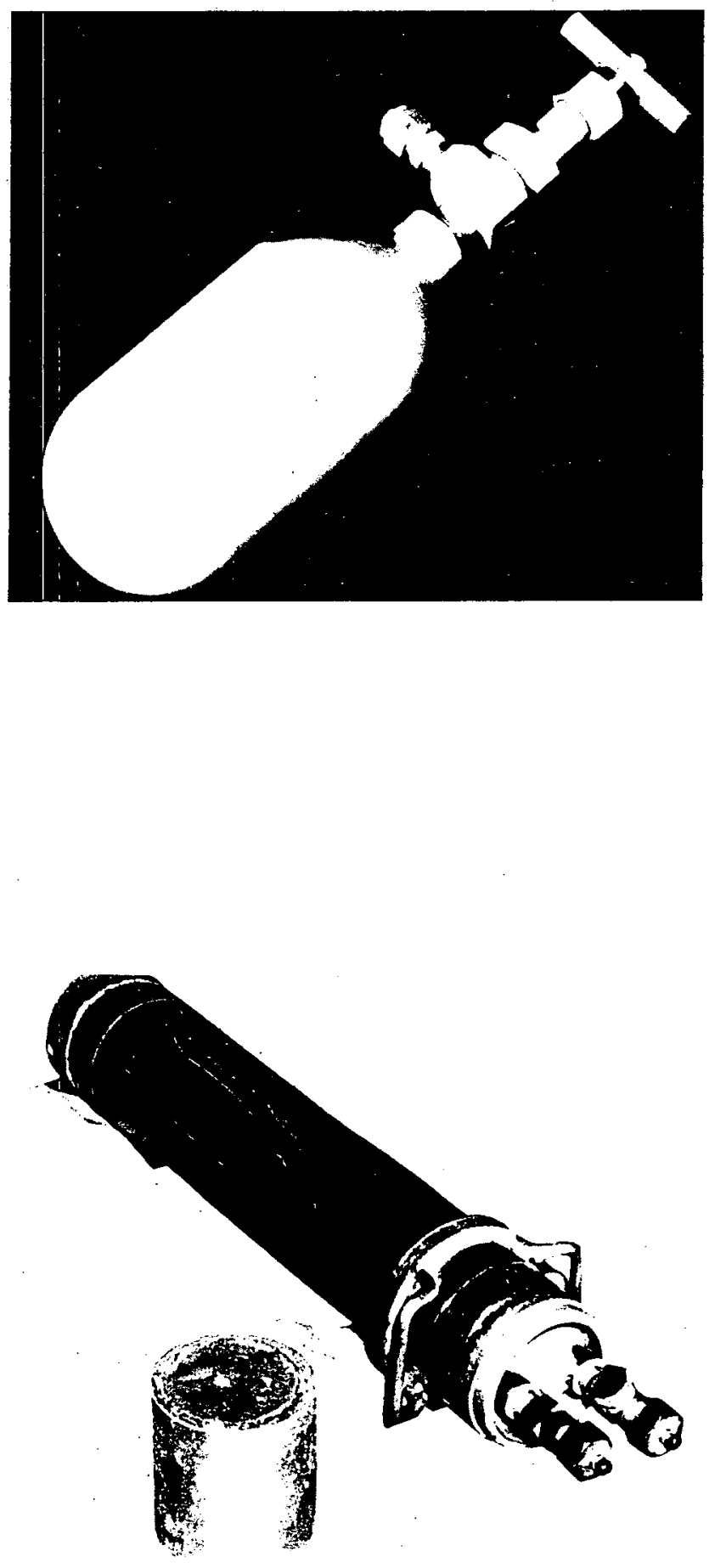


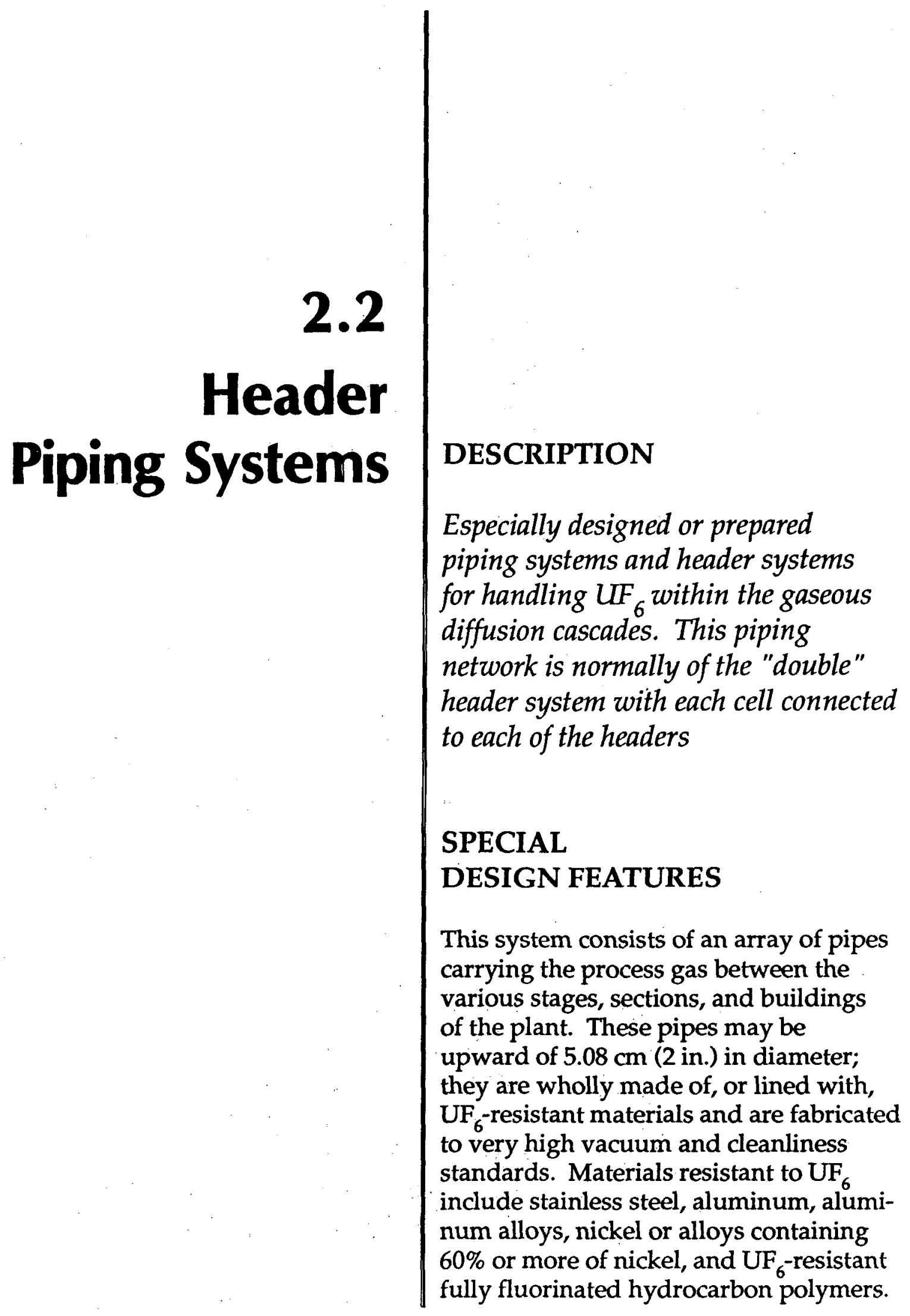



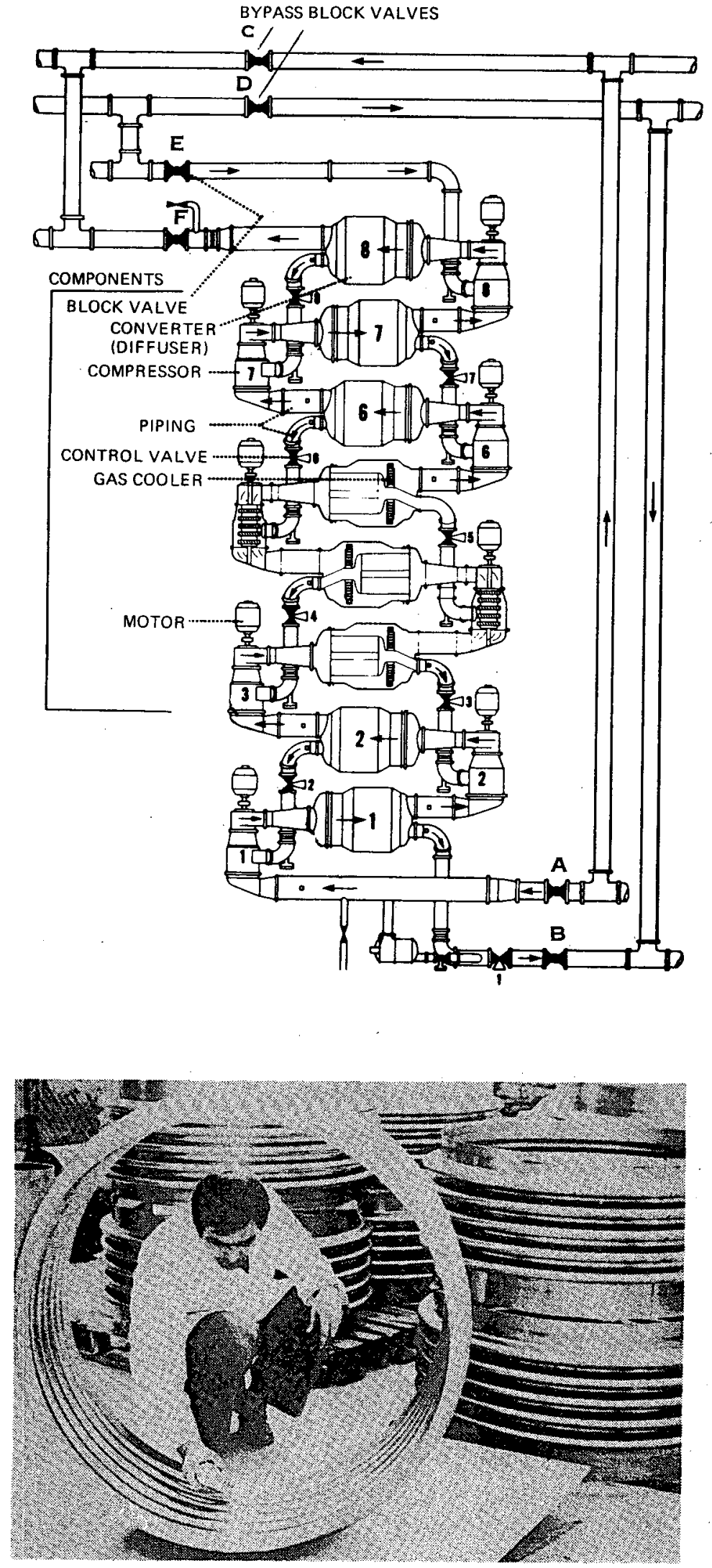

Details of a Header Piping System based on a U.S. design can be seen in this diagram. In normal cell operation, valves $A, B, E$, and $F$ are open, and valves $C$ and $D$ are closed. During cell bypass, the valve positions are reversed.
An example of a large metal bellows in the United States; these are an essential part of the Process Piping System and come in a wide variety of sizes from $2 \mathrm{~cm}(0.78 \mathrm{in}$.) in diameter or larger. Bellows made of materials such as nickel or high-nickel alloys would be resistant to UF ${ }_{6}$ attack and would be appropriate for diffusion plant service. 


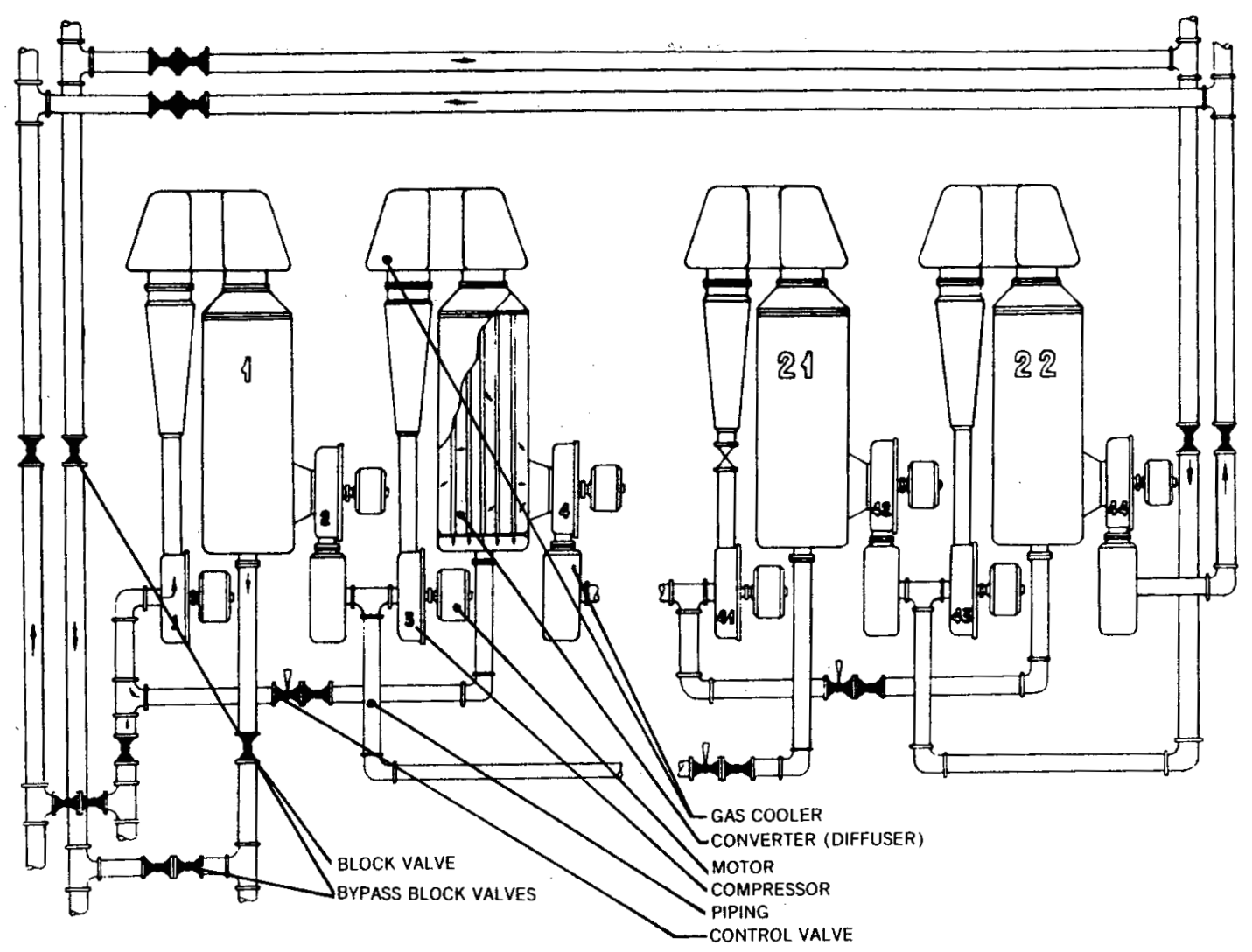

Details of a Header Piping System based on a Soviet design.

Process piping and equipment are usually connected, at least in larger sizes, by welded (commonly referred to as

Van Stone) joints made up of pairs of opposed flanges with nickel-plated facings. The flanges extend some distance beyond the outer pipe wall and are closed at their peripheries with carbon steel seal welds. Alternately, piping may use bolted flanges equipped with UF ${ }_{6}$-resistant gasketing material.

A typical two-ply bellows assembly. Expansion joints are a necessary part of the Process Piping System in order to allow for some pipe misalignment and to compensate for the effects of temperature changes on pipe lengths. The buffer connection permits the introduction of a buffering gas between the bellows and the sleeve.
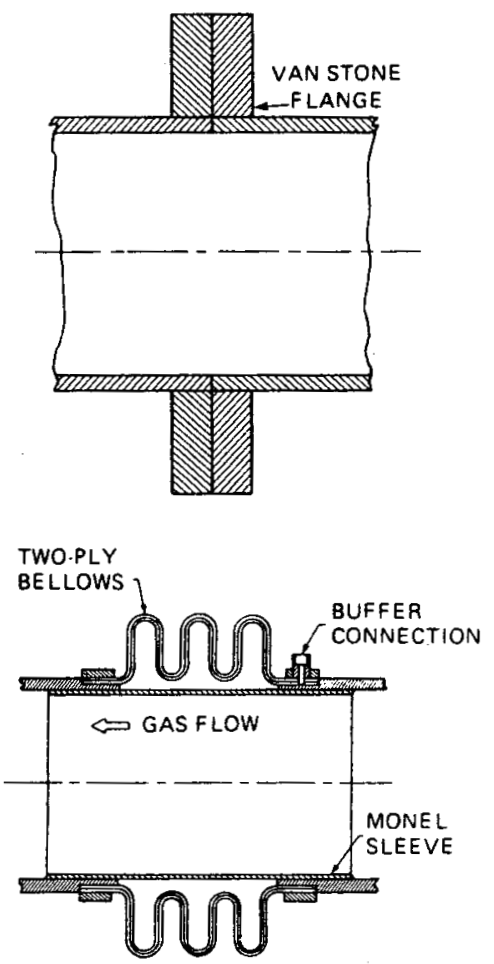


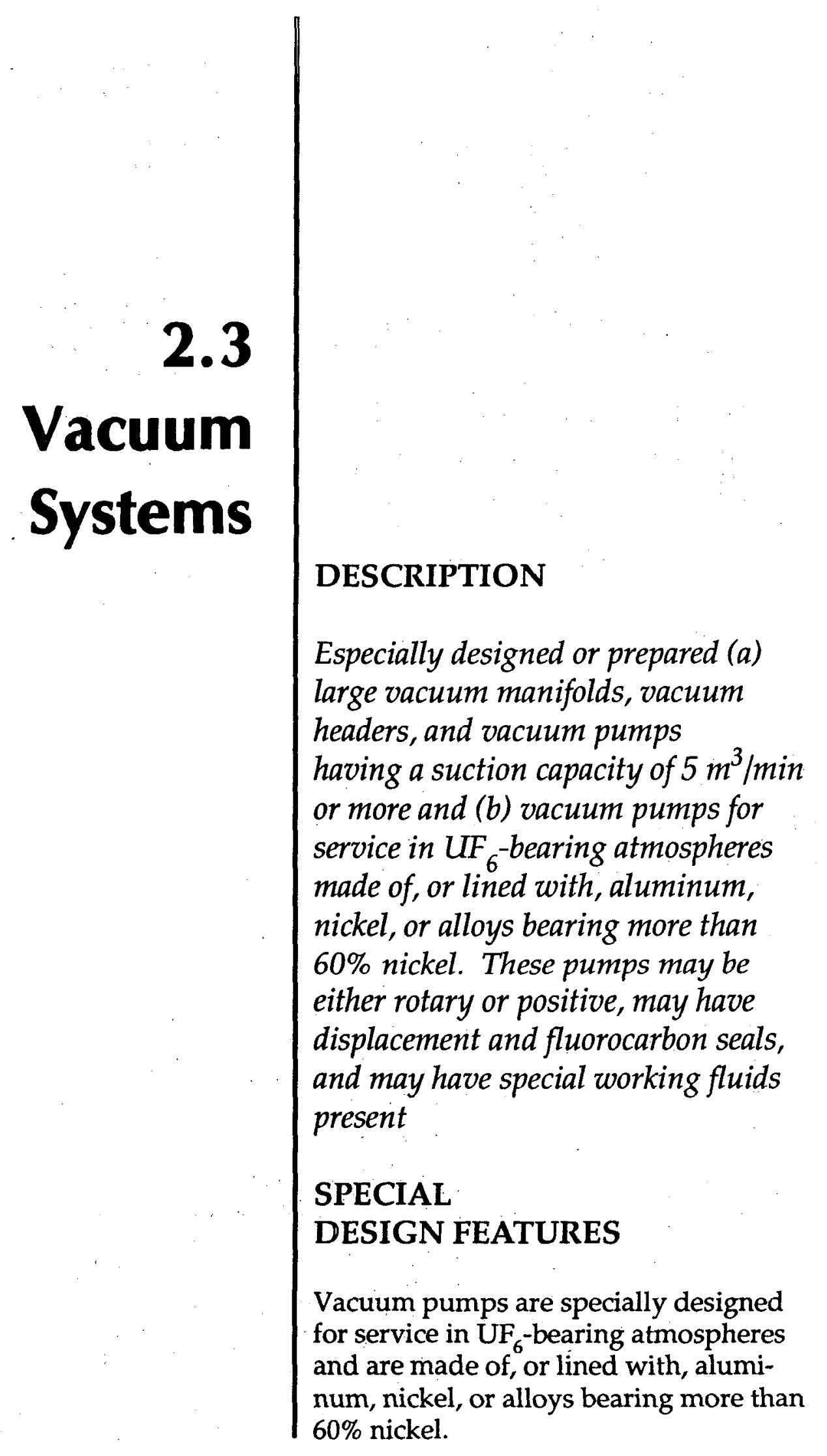



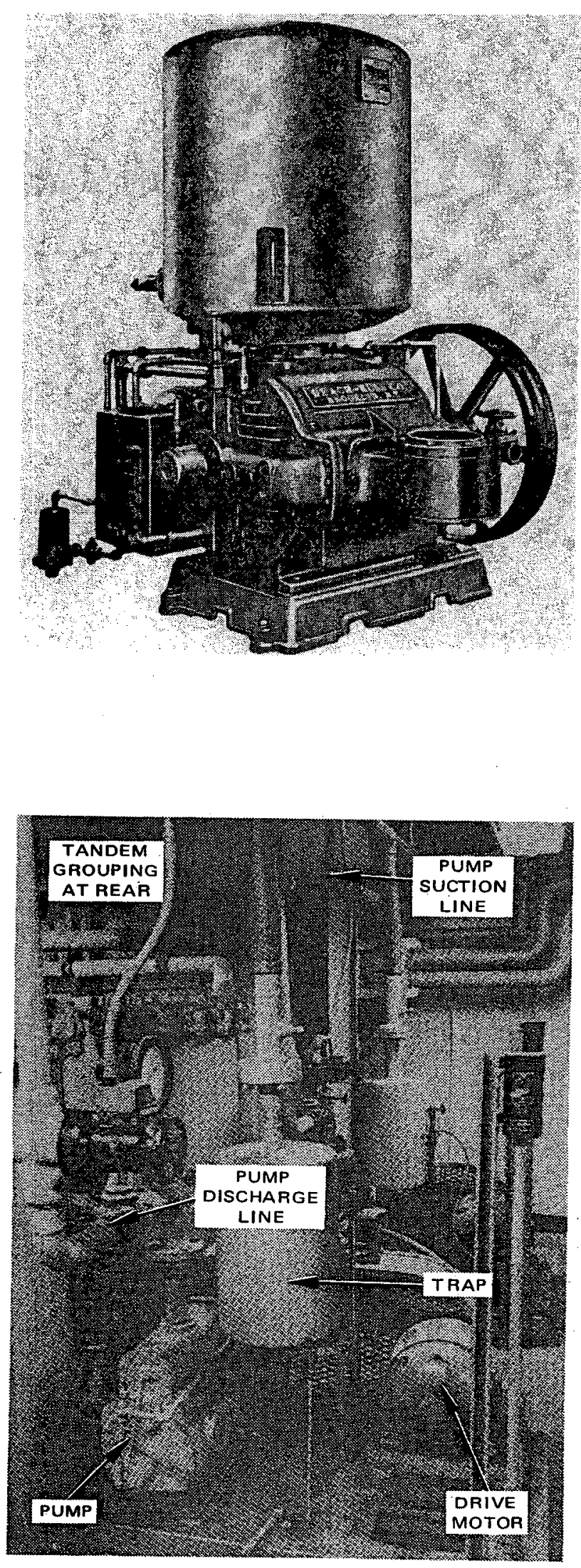

A pump having size and capacity characteristics used in a U.S. gaseous diffusion plant Process Vacuum System. Such a pump having working oil of fluorocarbon resistant to $U_{F_{6}}$ would be especially appropriate for $U F_{6}$ service.

\section{SPECIFICATIONS}

\begin{tabular}{ll}
\hline Pump displacement & $30 \mathrm{~m}^{3} / \mathrm{min}$. \\
Motor horsepower & 50 \\
Motor speed, rpm & 1200 \\
Oil capacity & \\
Standard "D" & $189 \mathrm{~L}$ \\
Vapor purge & $83 \mathrm{~L}$ \\
Piping sizes & \\
Suction & $20.3 \mathrm{~cm}$ \\
Discharge & $2.0 \mathrm{~cm}$ \\
Net weight with motor & $3084 \mathrm{~kg}$ \\
Length & $2.36 \mathrm{~m}$ \\
Width & $1.63 \mathrm{~m}$ \\
Height & $2.23 \mathrm{~m}$ \\
\hline
\end{tabular}

A vacuum pump and associated drive motor intended for service in a U.S. plant. It is necessary that such a system also have equipment such as traps and filters needed to protect against the effect of $U F_{6}$ contamination. 


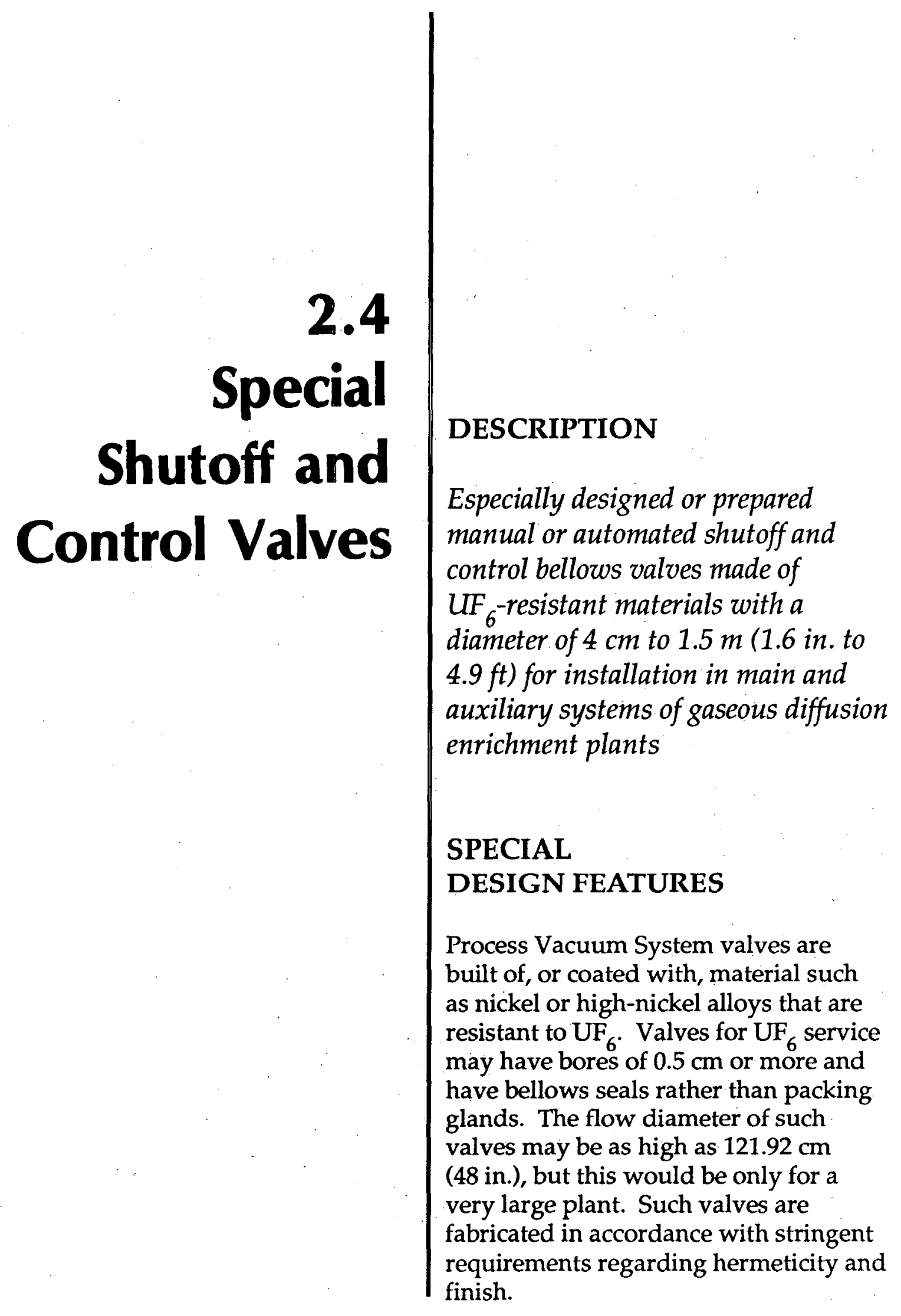




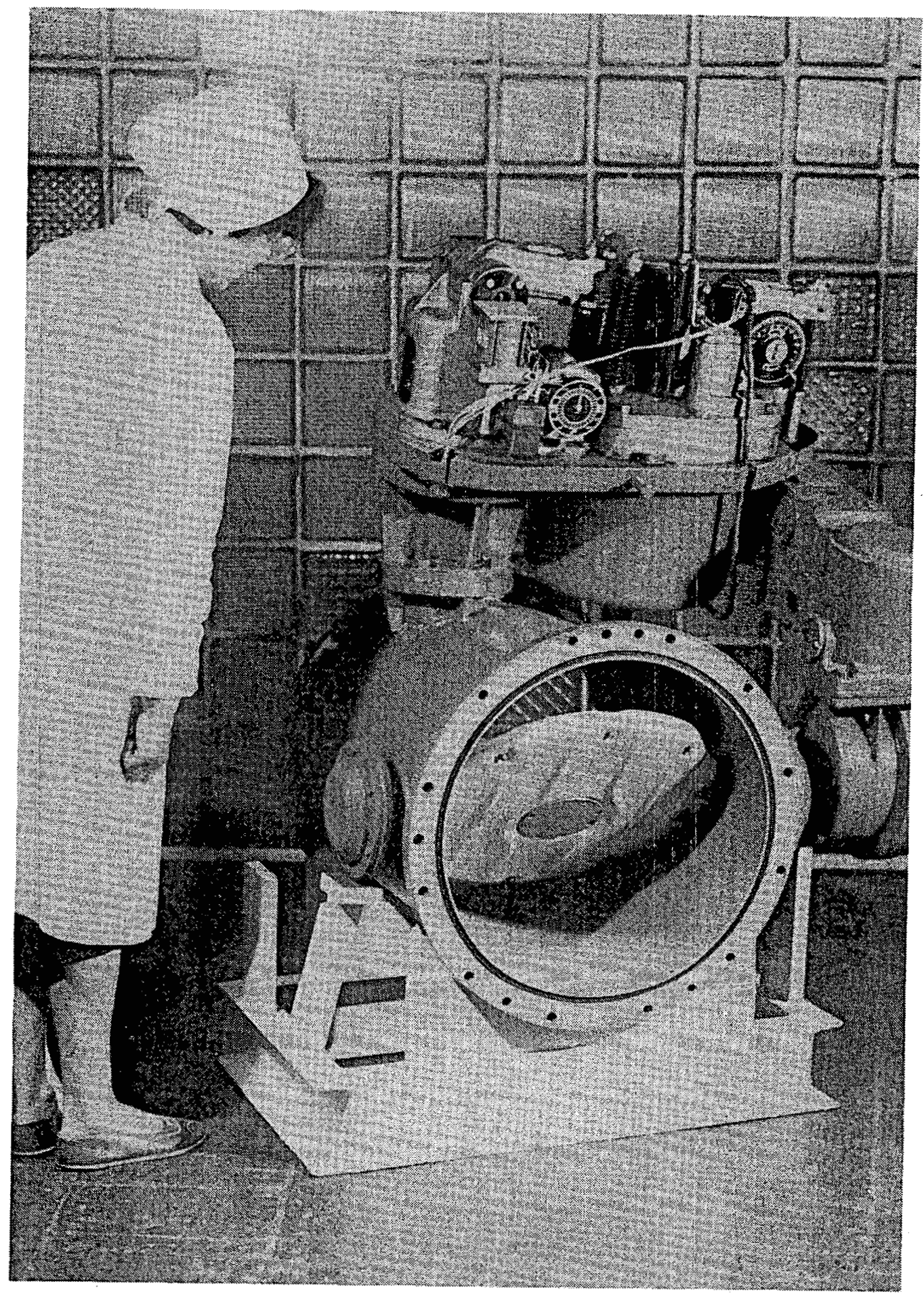

Shown is a Soviet control valve for the undiffused $\mathrm{UF}_{6}$ flow. 


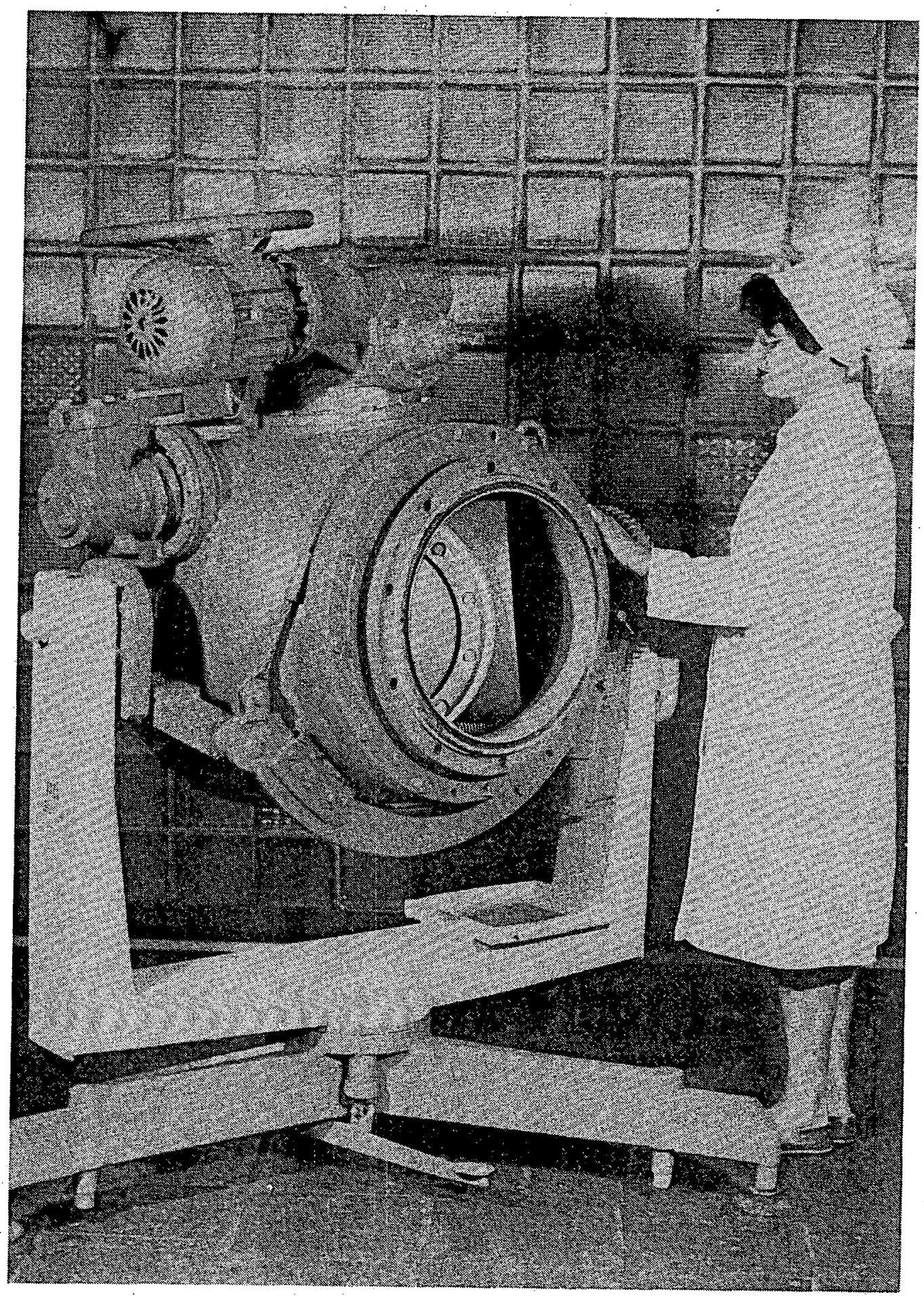

Shown is a Soviet motor-operated valve intended for $U F_{6}$ service in a line $40 \mathrm{~cm}$ (16 in.) in diameter. It is flanged, has internal bellows, and can be operated electrically or by hand. 

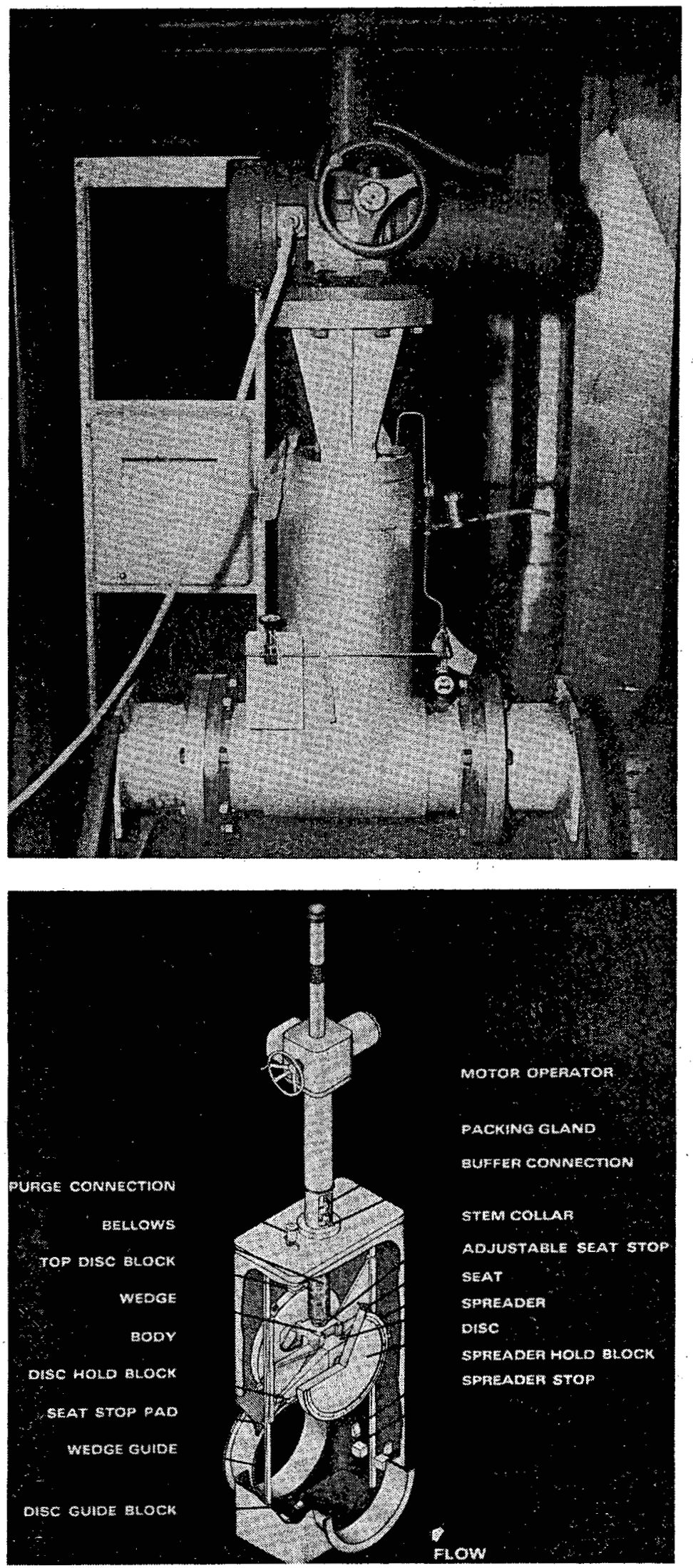

霖

称:

Shown is a motor-operated isolation valve used in the United States. Intended for UF ${ }_{6}$ service in a line $20 \mathrm{~cm}$ ( 8 in.) in diameter, it is flanged, has internal bellows, and can be operated electrically or by hand. The palve as shown was undergoing tests, and some additional probe lines are shown.

Schematic representation of a large motor-operated process block valve used in the United States. The various parts are used as either elements necessary for valve operation, requirements for ensuring seating integrity, or requirements for buffering the bellows system or purging the valoe of process gas when it is to be worked on. Such valves could come with bores of as little as $3 \mathrm{~cm}$ (1.2 in.), but the central element would be the presence of bellows for isolation of the Process Vacuum System from the atmosphere. 
Schematic representation of a large motor-operated (or by hand) process block valve used in a Soviet gaseous diffusion plant. The carious parts are used either as elements necessary for valve operation, as a requirement for ensuring seating integrity, or as a requirement for buffering the bellows system when it is closed or purging the valve of process gas when it is open.
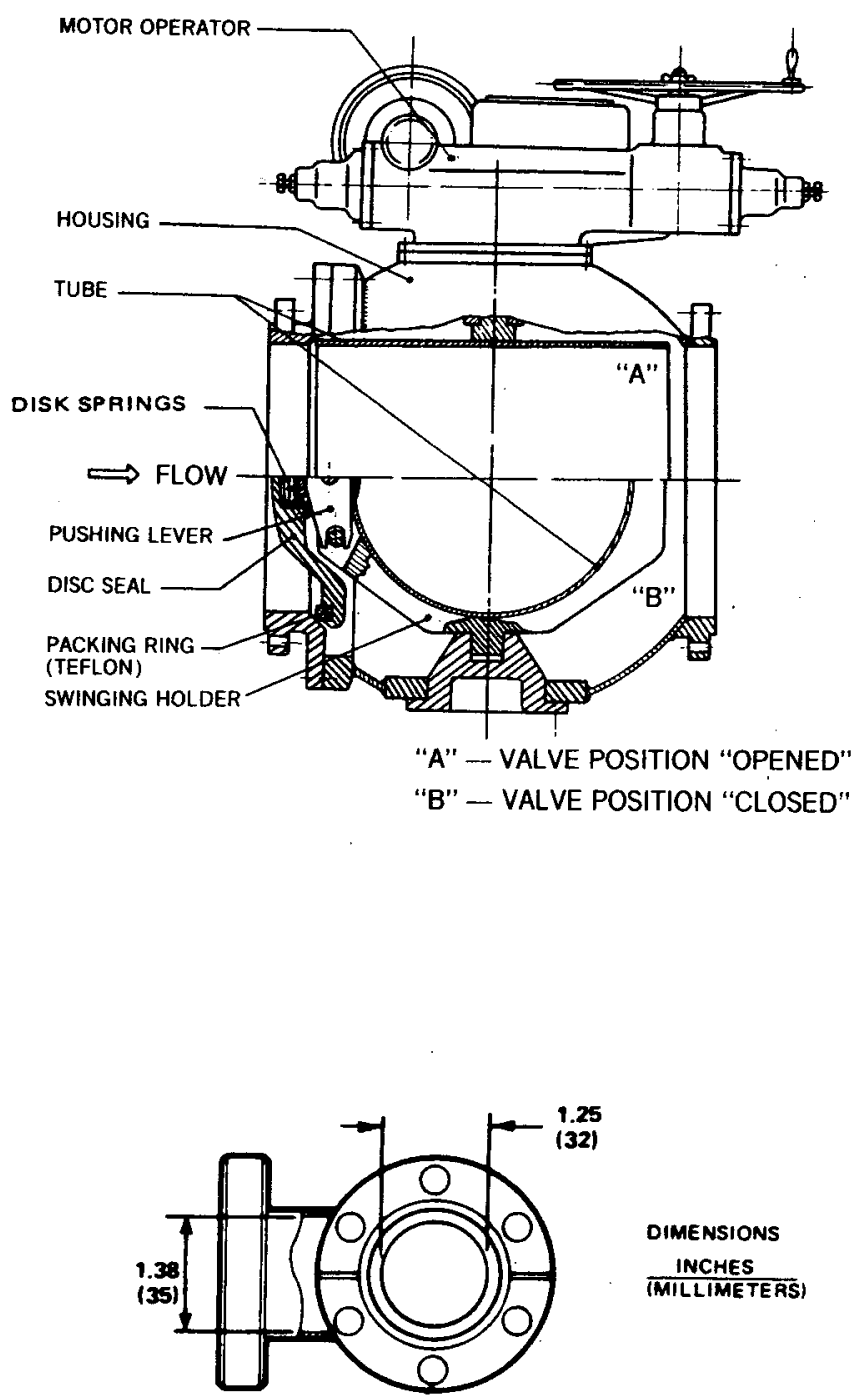

DIMENSIONS

INCHES

MILLIMETERS
A small process block valve such as that used in the United States (see schematic at right) may be pneumatically operated. The solenoid control valve on the air inlet admits air; this operates on a piston and opens the valve against the spring pressure. When he solenoid is deactuated, the air flow is cut off, and the spring pressure forces the valve closed. 


\section{5 \\ $\mathrm{UF}_{6}$ Mass \\ Spectrometers/ \\ Ion Sources}

\section{DESCRIPTION}

Especially designed or prepared magnetic or quadrupole mass spectrometers capable of taking on-line samples of feed, product, or tails from UIF ${ }_{6}$ gas streams and having all of the following characteristics:

(1) unit resolution for mass greater than 320; (2) ion sources constructed of, or lined with, nichrome or Monel or nickel plated; (3) electron bombardment ionization sources; and (4) a collector system suitable for isotopic analysis

\section{SPECIAL}

\section{DESIGN FEATURES}

The key elements of this instrument are the unit resolution of mass greater than 320 , the presence of an ion bombardment source in a $\mathrm{UF}_{6}$-resistant chamber made of, or lined with, nickel, nichrome, or Monel, and a collector system capable of taking on-line samples for two or more isotopic species. 


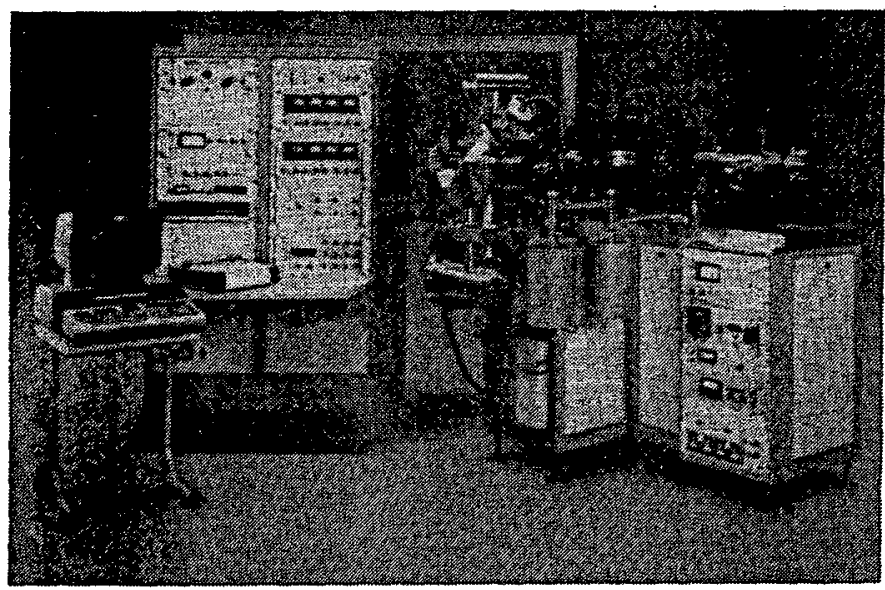

In the United States, mass spectrometers to measure concentrations of UF ${ }_{6}$ samples come in a wide range of dimensions and configurations. In this photograph, the sample and ion source are in the equipment on the left, while measurements are recorded in the equipment on the right.

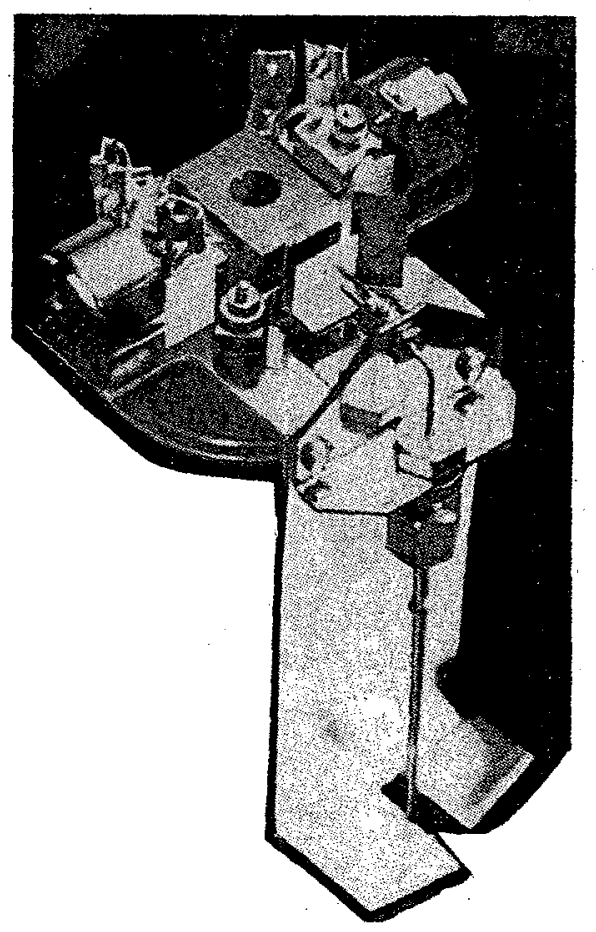

U.S. ion sources are made of, or are internally lined with, materials that are corrosize-resistant to $U F_{6}$. An ion source ionizes molecuies from a gas sample and shoots them in a collimated beam down a curved channel. Only the molecules with the desired mass track the channel to a collecting device that samples the different isotopes. 
Appendix

\section{GASEOUS DIFFUSION TRIGGER LIST* \\ OCTOBER $1989^{\dagger}$}

\section{Introductory Note}

In the gaseous diffusion method of uranium isotope separation, the main technological assembly is a special porous gaseous diffusion barrier, heat exchanger for cooling the gas (which is heated by the process of compression), seal valves and control valves, and pipelines. Inasmuch as gaseous diffusion technology uses uranium hexafluoride $\left(\mathrm{UF}_{6}\right.$ ), all equipment, pipeline and instrumentation surfaces (that come in contact with the gas) must be made of materials that remain stable in contact with $\mathrm{UF}_{6}$. A gaseous diffusion facility requires a number of these assemblies, so that quantities can provide an important indication of end use.

The auxiliary systems, equipment and components for gaseous diffusion enrichment plants are the systems of plant needed to feed $\mathrm{UF}_{6}$ to the gaseous diffusion assembly to link the individual assemblies to each other to form cascades (or stages) to allow for progressively higher enrichments and to extract the "product" and "tails" $\mathrm{UF}_{6}$ from the diffusion cascades. Because of the high inertial properties of diffusion cascades, any interruption in their operation, and especially their shutdown, leads to serious consequences. Therefore, a strict and constant maintenance of vacuum in all technological systems, automatic protection from accidents, and precise automated regulation of the gas flow is of importance in a gaseous diffusion plant. All this leads to a need to equip the plant with a large number of special measuring, regulating and controlling systems.

Normally $\mathrm{UF}_{6}$ is evaporated from cylinders placed within autoclaves and is distributed in gaseous form to the entry point by way of cascade header pipework. The "product" and "tails" $\mathrm{UF}_{6}$ gaseous streams flowing from exit points are passed by way of cascade header pipework to either cold traps or to compression stations where the $\mathrm{UF}_{6}$ gas is liquified prior to onward transfer into suitable containers for transportation or storage. Because a gaseous diffusion enrichment plant consists of a large number of gaseous diffusion assemblies arranged in cascades, there are many kilometers of cascade header pipework, incorporating thousands of welds and substantial amounts of repetition of layout. The equipment, components and piping systems are fabricated to very high vacuum and cleanliness standards. The items listed below either come into direct contact with the $\mathrm{UF}_{6}$ process gas or directly control the flow within the cascade. All surfaces which come into contact with the process gas are wholly made of, or lined with, $\mathrm{UF}_{6}$-resistant materials.

For the purposes of this annex the materials resistant to corrosion by $\mathrm{UF}_{6}$ include stainless steel, aluminum, aluminum alloys, aluminum oxide, nickel or alloys containing 60 percent or more nickel, and $\mathrm{UF}_{6}$-resistant fully fluorinated hydrocarbon polymers.

\section{ESPECIALLY DESIGNED OR PREPARED ASSEMBLIES AND COMPONENTS FOR USE IN GASEOUS DIFFUSION ENRICHMENT}

\subsection{Gaseous Diffusion Barriers}

Especially designed or prepared thin, porous filters, with a pore size of $100-1000 \AA$ (angstroms), a thickness of $5 \mathrm{~mm}$ or less, and for tubular forms, a diameter of $25 \mathrm{~mm}$ or less, made of metallic, polymer or ceramic materials resistant to corrosion by $\mathrm{UF}_{6}$, and especially prepared compounds or powders for the manufacture of

\footnotetext{
- Pending Annex (unedited and printed verbatim) to "Communications Received from Members Regarding the Export of Nuclear Materials and of Certain Categories of Equipment and Other Material," INFCIRC/209, International Atomic Energy Agency, Vienna.

Incorporates editorial revisions suggested to add clarity to the list.
} 
such filters. Such compounds and powders include nickel or alloys containing 60 percent or more nickel, aluminum oxide, or $\mathrm{UF}_{6}$-resistant fully fluorinated hydrocarbon polymers having a purity of 99.9 percent or more, a particle size less than 10 microns, and a high degree of particle size uniformity, which are especially prepared for the manufacture of gaseous diffusion barriers.

\subsection{Diffuser Housings}

Especially designed or prepared hermetically sealed cylindrical vessels greater than $30 \mathrm{~cm}$ in diameter and greater than $90 \mathrm{~cm}$ in length, or rectangular vessels of comparable dimensions, which have an inlet connection and two outlet connections all of which are greater than $5 \mathrm{~cm}$ in diameter, for containing the gaseous diffusion barrier, made of or lined with $\mathrm{UF}_{6}$-resistant materials and designed for horizontal or vertical installation.

\subsection{Compressors and gas blowers}

Especially designed or prepared axial, centrifugal, or positive displacement compressors, or gas blowers with a suction volume capacity of $1 \mathrm{cu} \mathrm{m} / \mathrm{min}$ or more of $\mathrm{UF}_{6}$, and with a discharge pressure of up to several hundred $\mathrm{kN} / \mathrm{m}^{2}$ (100 psi), designed for long-term operation in the $\mathrm{UF}_{6}$ environment with or without an electrical motor of appropriate power, as well as separate assemblies of such compressors and gas blowers. These compressors and gas blowers have a pressure ratio between $2 / 1$ and $6 / 1$ and are made of, or lined with, materials resistant to $\mathrm{UF}_{6}$.

\subsection{Rotary shaft seals}

Especially designed or prepared vacuum seals, with seal feed and seal exhaust connections, for sealing the shaft connecting the compressor or the gas blower rotor with the driver motor so as to ensure a reliable seal against in-leaking of air into the inner chamber of the compressor or gas blower which is filled with UF 6 . Such seals are normally designed for a buffer gas in-leakage rate of less than $1000 \mathrm{cubic} \mathrm{cm} / \mathrm{min}$.

\subsection{Heat Exchangers for Cooling UF 6}

Especially designed or prepared heat exchangers made of or lined with UF ${ }_{6}$-resistant materials (except stainless steel) or with copper or any combination of those metals, and intended for a leakage pressure change rate of less than $10 \mathrm{~N} / \mathrm{m}^{2}(0.0015 \mathrm{psi})$ per hour under a pressure difference of $100 \mathrm{kN} / \mathrm{m}^{2}(15 \mathrm{psi})$.

\section{ESPECIALLY DESIGNED OR PREPARED AUXILIARY SYSTEMS, EQUIPMENT AND COMPONENTS FOR USE IN GASEOUS DIFFUSION ENRICHMENT}

\subsection{Feed Systems/Product and Tails Withdrawal Systems}

Especially designed or prepared process systems, capable of operating at pressures of $300 \mathrm{kN} / \mathrm{m}^{2}$ (45 psi) or less, including:

Feed autoclaves (or systems), used for passing $\mathrm{UF}_{6}$ to the gaseous diffusion cascades;

Desublimers (or cold traps) used to remove $\mathrm{UF}_{6}$ from diffusion cascades;

Liquefaction stations where $\mathrm{UF}_{6}$ gas from the cascade is compressed and cooled to form liquid $\mathrm{UF}_{6}$;

"Product" or "tails" stations used for transferring $\mathrm{UF}_{6}$ into containers. 


\subsection{Header Piping Systems}

Especially designed or prepared piping systems and header systems for handling $\mathrm{UF}_{6}$ within the gaseous diffusion cascades. This piping network is normally of the "double" header system with each cell connected to each of the headers.

\subsection{Vacuum Systems}

(A) Especially designed or prepared large vacuum manifolds, vacuum headers and vacuum pumps having a suction capacity of 5 cubic $\mathrm{m} /$ minute ( 5 cubic metres per minute) or more.

(B) Vacuum pumps especially designed for service in $\mathrm{UF}_{6}$-bearing atmospheres made of, or lined with, aluminum, nickel, or alloys bearing more than 60 percent nickel. These pumps may be either rotary or positive, may have displacement and fluorocarbon seals, and may have special working fluids present.

\subsection{Special Shut-off and Control Valves}

Especially designed or prepared manual or automated shut-off and control bellows valves made of $\mathrm{UF}_{6}$-resistant materials with a diameter of $4 \mathrm{~cm}$ to $1.5 \mathrm{~m}$ for installation in main and auxiliary systems of gaseous diffusion enrichment plants.

\subsection{UF 6 Mass Spectrometers/Ion Sources}

Especially designed or prepared magnetic or quadrupole mass spectrometers capable of taking "on-line" samples of feed, product or tails, from $\mathrm{UF}_{6}$ gas streams and having all of the following characteristics:

(A) Unit resolution for mass greater than 320 ;

(B) Ion sources constructed of or lined with nichrome or Monel or nickel plated;

(C) Electron bombardment ionization sources;

(D) Having a collector system suitable for isotopic analysis. 